Rev. Elev. Med. Vét. Pays trop., 1965, 18, 3 (249-282).

\title{
Aphosphorose et botulisme au Sénégal
}

\author{
por H. CALVET, P. PICART, M. DOUTRE ef J. CHAMBRON
}

\begin{abstract}
RÉSUMÉ
L'affection animale observée au Sénégal, dans la régıon du Ferlo, et connue localement sous le nom de «Gniedro » ou de «maladie des forages» rappelle par son étiologie, sa symptomatologie et sa pathogénie le Lamsiekte décrit par THEILER en Afrique du Sud.

Elle résulte de l'association d'un trouble nutritionnel, essentiellement une carence en phosphore, et d'une toxémie botulique.

Les analyses biochimiques, au Laboratoire de Dakar, ont mis en évidence l'état d'aphosphorose chez les animaux. Les analyses chimiques des sols, des eaux ê des fourrages reflètent la même insuffisance en cet élément.

L'hypothèse de botulisme se voit confirmée par le succès de la sérothérapie spécifique et de la prophylaxie à l'aide des anatoxines botuliques $C$ et $D$.

La toxine botulique a été révélée par séro-neutralisation chez la souris, mais jusqu'à ce jour l'isolement de Clostridium botulinum n'a pu être réalisé.
\end{abstract}

\section{A. - INTRODUCTION}

Depuis plusieurs années sévit sur le cheptel d'une large région d'élevage du Sénégal une maladie à allure enzootique connue sous le nom vernaculaire de "Gniedio» (*) et sous l'appellation locale de «maladie des forages». Cependant, cette dernière dénomination, qui paraît attribuer aux forages profonds une responsabilité directe dans l'étiologie de l'affection, est impropre, la distribution géographique de la maladie et son caractère longtemps indéterminé constituant sa seule justification.

Les premières mentions concernant cetfe affection apparaissent en juillet 1959 dans un rapport de la circonscription de Linguère. En 1960, des experts de la SERESA font état, dans une étude traitant de la commercialisation du bétail, de paraplégies conduisant rapidement à la mort (43).

(*) Dans la langue peule « Gniedio » signifie maladie des membres.
Par la suite la maladie, prenant une rapide extension, devient un sujet d'inquiétude pour tous les éleveurs du Ferlo et l'objet d'une préoccupation constante pour le Service de l'Elevage du Sénégal. En effet, le troupeau menacé constitue une partie importante du cheptel national. Evalué à plus de 600.000 têtes, il esf essentiellement constitué de zébus appartenant à des propriétaires peuls, attachés à leur mode de vie nomade.

En raison du caractère extensif de l'élevage, des déplacements fréquents et imprévisibles des pasteurs, de leur répugnance à fournir des données chiffrées permettant d'évaluer leur effectif, les pertes annuelles sont difficiles à déterminer d'une façon précise. Néanmoins les renseignements, recueillis au cours des campagnes de vaccination ou de mission d'étude menées dans toute cette zone, permettent de conclure à une mortalité importante.

A titre d'exemple, nous citerons les informations obtenues en juillet 1963, lors d'une prospection portant sur cinq campements, tous situés à proximité du forage de Lagbar. 
Chacun des troupeaux comprend, à l'origine 200 à 300 têtes. Dans le premier rassemblement, 100 bovins ont succombé pendant les cing derniers mois; dans le second, 21 animaux viennent de disparaître, tandis que le troisième a présenté 10 cas d'évolution rapide. Au cours de la même période 30 morts sont dénombrés dans la quatrième communauté et 50 autres signalés dans un troupeau stationné à proxımité. Enfin le dernier éleveur rencontré rapporte des pertes dépassant 80 têtes.

Ces évaluations, effectuées dans une zone réputée pour sa forte endémicité, ne peuvent évidemment pas être étendues à l'ensemble du Ferlo. Elles permettent cependant de souligner la gravité de la maladie, une des plus sévères qui frappe, à l'heure actuelle, l'élevage du sahel sénégalais.

L'étude de cette affection a été entreprise dès 1962 par les divers services du Laboratoire national de l'Elevage et de Recherches vétérinaires du Sénégal (24).

Les premières observations réalisées dans la région dite «des six forages» donnent lieu à des autopsies nombreuses, des examens hématologiques et histologiques divers. L'isolement d'un virus ou d'un germe échoue: aucun parasite n'est décelé dans le sang. Cependant, rapidement les symptômes manifestés par certains malades permettent d'envisager un trouble du métabolisme phospho-calcique. Une nouvelle orientation est désormais donnée aux recherches.

Des animaux atteints sont alors transportés à Dakar et gardés en stabulation au laboratoire.

En avril 1962, un premier lot est hospitalisé, suivi, début 1963, d'un autre plus important. Ces zébus, dont l'état se trouve aggravé par le transport, auront une courte survie. Seule une vache résistera. Les paralysies, le refus de s'alimenter et de boire font que, dans les 10 jours, tous succombent en dépit des traitements expérimentaux institués.

Des prélèvements systématiques de sang et d'urine sont effectués à des fins de dosages portant sur les protéines sanguines et l'urée, les taux plasmatiques et urinaires du phosphore, calcıum, sodıum, potassium et de la créatinine. Les os des animaux morts sont également soumis ò l'analyse.

L'interprétation de ces recherches biochimiques s'avère délicate. Les résultats présentent souvent de grandes variations probablement explicables par l'état de marasme physiologique auquel parviennent les animaux en fin de maladie.

Toutefors, l'existence d'une perturbation du métabolisme phospho-calcique se confirme. Au niveau du squelette, les analyses mettent en évidence un certaın degré d'ostéomalacie avec un rapport matières minérales/protides inférieur à la normale (25).

En juillet 1963, deux nouvelles prospections sont effectuées dans la zone de forte endémicité des environs de Lagbar. Des éléments concernant la symptomatologie et la pathogénie de l'affection sont recueillis. Ils permettent de dégager une hypothèse de travail comportant, d'une part, l'étude du trouble nutritionnel qui s'extériorise de façon diverse (le pica étant un des signes caractéristiques) et, d'autre part, la mise en évidence d'une toxémie, vraisemblablement d'origine botulique, responsable des évolutions rapidement mortelles.

Les recherches ne tardent pas à dégager l'importance que revêt la connaissance du milıeu naturel dans l'étude de cette maladie. En effet, certaines particularités géologiques, hydrologiques, botaniques, contribuent à expliquer l'existence de cette affection. Son apparition et son extension paraissant plus spécialement liées à l'évolution des techniques d'élevage survenue dans cette région à la suite des grands travaux d'hydraulique qui y ont été entrepris. Ces considérations justifient le large développement donné au chapitre suivant.

\section{B. - MILIEU NATUREL}

Empruntant son nom à une vallée fossile, le Ferlo constitue une vaste plaine sahélienne, d'une superficie approximative de $40.000 \mathrm{~km}^{2}$, située dans la partie septentrionale du Sénégal (cartes l et II). Ses limites, assez imprécises, dessinent en gros un quadrilatère irrégulier. Le côté occidental, marqué approximativement par le $15^{\mathrm{e}}$ degré de longitude Ouest, s'inscrit entre les $13^{\mathrm{e}}$ et $15^{\mathrm{e}}$ degrés de latitude Nord. Le bord oriental, porté par le $13^{\mathrm{e}}$ degré de longıtude, est compris entre les latitudes $15^{\circ} 20^{\prime}$ et $14^{\circ}$ Nord. Il touche par sa périphérie le Fouta sénégalais, le Baol, le Djolof, le Boundou et atteint sur ses confins méridionaux la zone arachidière. 


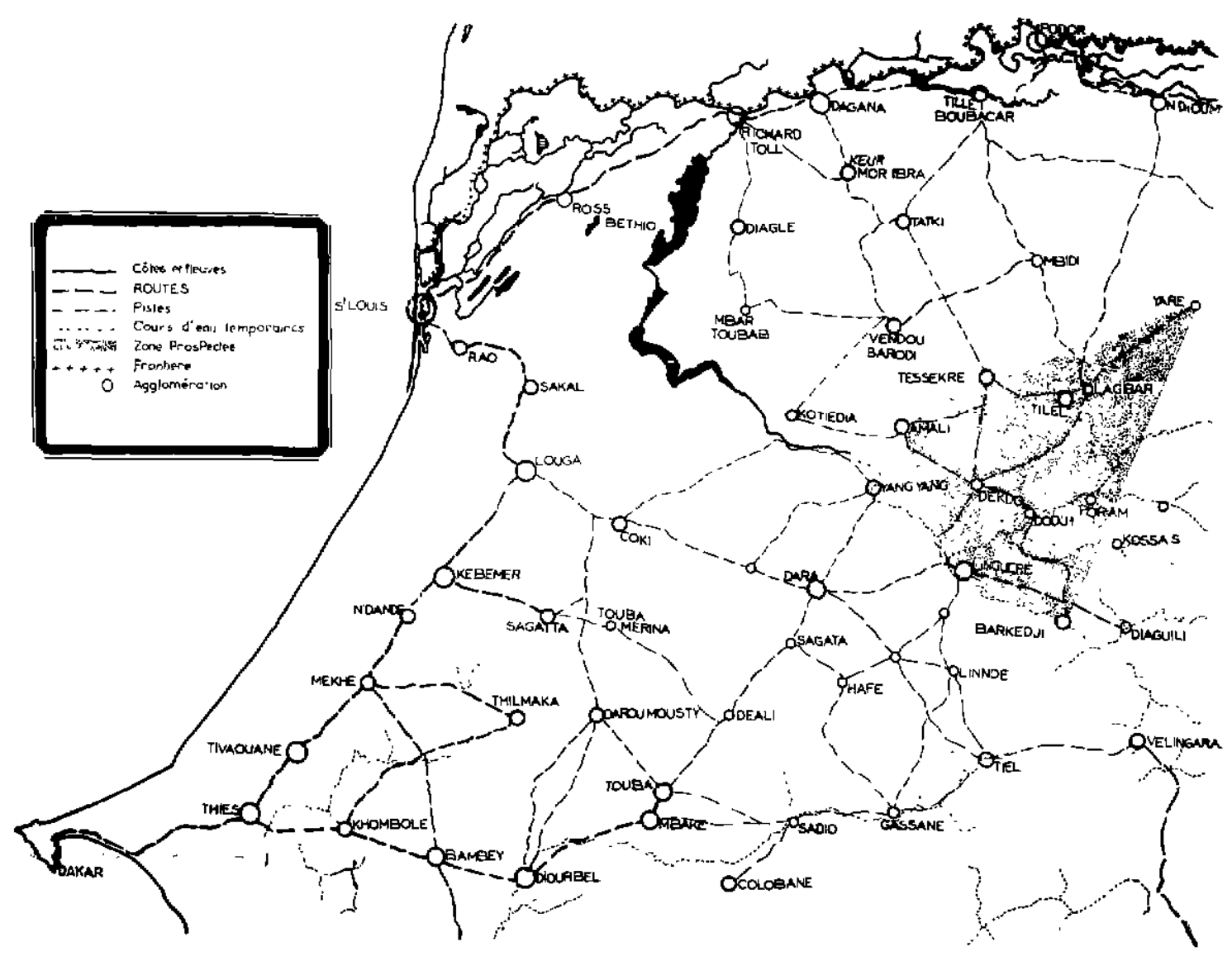

Carte no 1. - Situation du Ferlo au Sénégal.

\section{la Structure géologique et pédologique.}

Géologiquement, le Ferlo représente la partie sud-est du bassin sédimentaire sénégalo-mauritanien. Sur le vieux socle granitique primaire, se sont superposées, aux différentes périodes, des formations plus récentes.

Les coupes géologiques montrent :

- au secondaire : les sables à eau douce du Maestrichtien :

- au tertiaire : la cauche de grès argileux du continent termınal, ce dernier profil, d'une épaisseur considérable, résultant d'une longue période d'érosion et de destruction des massifs anciens :

- au début du quaternaire, intervient le processus de latéritisation qui recouvre les formations précédentes d'une croûte mince qu'entaillent les vallées fluviales.

Finalement, l'érosion éolienne coiffe le Ferlo. de dunes rouges de sable ferrugineux appartenont à l'ensemble dit «Erg sénégalo-mauritanien $\gg(*)$.

Cette évolution géologique a conféré aux sols du Ferlo une certanne uniformité. Ceux qui portent un tapis végéłal suffisant pour intéresser l'élevage sont essentiellement constitués (33) :

(*) Nous devons ces renseignements à l'amabilité du Pr. Y. SAINT MARTIN auquel nous adressons tous nos remerciements. 


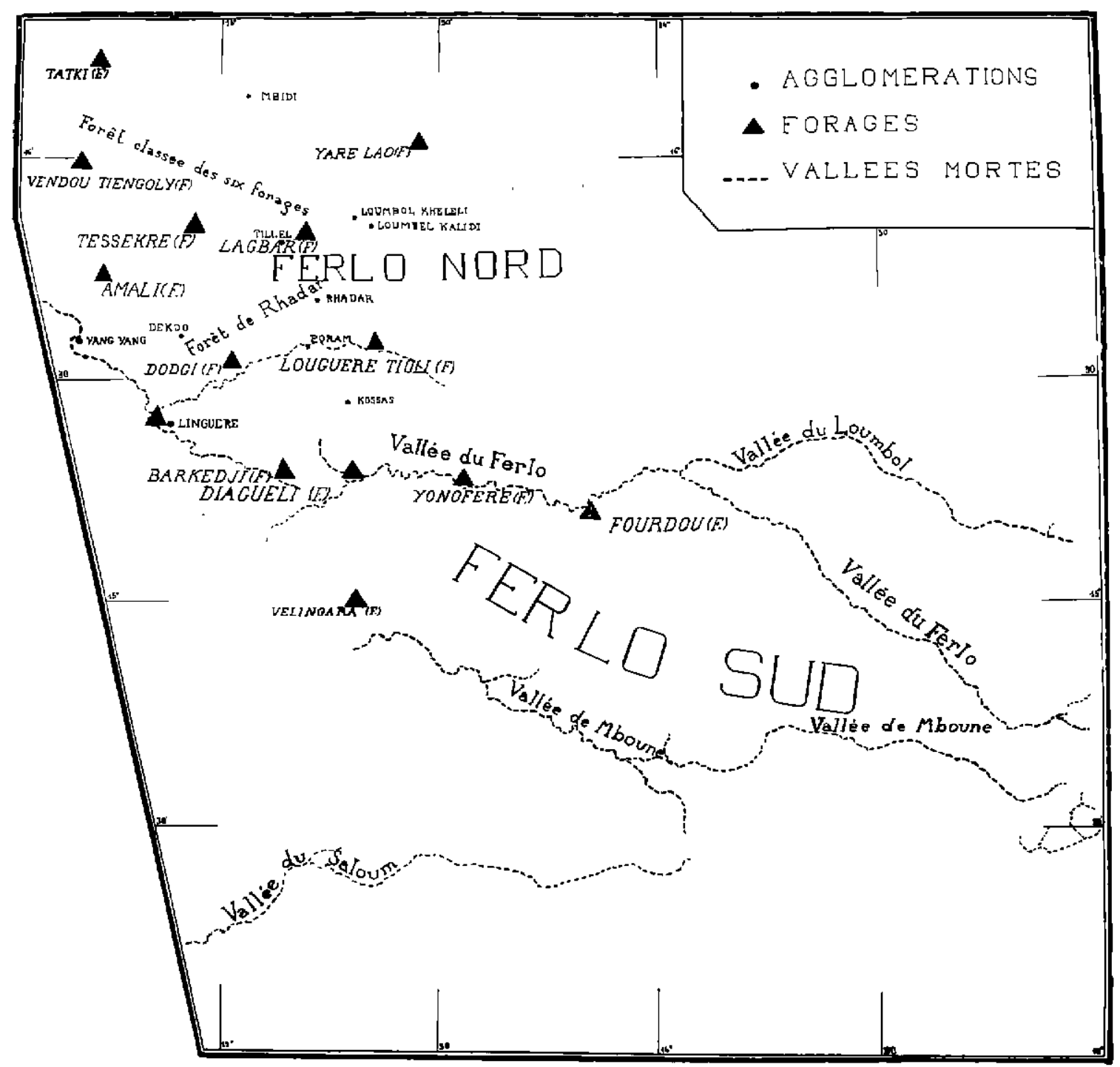

Carte no 2. - Carte du Ferlo.

- Por des dunes sablonneuses peu élevées, d'origıne éolienne. Ces sols, peu profonds, reposent généralement sur une cuirasse ferrugineuse, ou sur des produits remaniés qui en dérivent.

Très répandues dans l'ensemble du Ferlo, ces dunes occupent de vastes surfaces planes. Elles sont caractérisées dans le nord par une texture plus grossière où se mêle l'argile. Dans le Ferlo sud, par contre, la granulométrie est plus fine et la texture argilo-sableuse ou sabloargileuse plus ou moins limoneuse.
- Par des sols sablonneux ou sablo-argileux, plus ou moins compacts, d'origine complexe, qui occupent de grandes superficies dans les secteurs inter-dunes. lls proviennent des éléments fins dunaires qui ont été entraînés par les pluies ou de la désagrégation du continent terminal.

- Par des sols hydromorphes, qui se rencontrent dans le fond et le pourtour des mares temporaires.

- Por des affleurements calcaires ou marnocalcoires. Ces calottes calcaires jovent par leur 
faible surface un rôle limité. Certaines portent en saison sèche des pâturages recherchés par les éleveurs. La présence d'Aristida mutabilis, en tant qu'espèce dominante, ef le fait que les animaux lèchent le sol, exercent une influence favorable sur les troupeaux.

Enfin, il faut signaler quelques sols salins, rencontrés dans la région de Yang Yang. Ils permettaient les «cures hydro-minérales» prévues périodiquement par les éleveurs il y a encore quelques années.

\section{$2^{\circ}$ Climat ef hydrographie.}

Le clımat, de type sahélo-soudanien au nord et soudano-sahélien au sud, se caractérise par des températures élevées et une longue saison sèche.

La pluviosité moyenne ef le nombre de jours de pluie augmentent à mesure que l'on se dirige vers le sud (Matam : $536 \mathrm{~mm}$ avec 37 jours de pluie, Tambacounda : $942 \mathrm{~mm}$ avec 67 jours). Les précipitations ont lieu généralement du début août à la fin septembre, elles sont parfois interrompues par une période de sécheresse intercalaire néfaste à la végétation (22).

De fortes chaleurs sont enregistrées de février à juillet, le thermomètre indiquant souvent plus de $40^{\circ} \mathrm{C}$. Les écarts diurnes sont alors très marqués $\left(18^{\prime a ̀ ~} 20^{\circ} \mathrm{C}\right.$ ) et l'hygrométrie très faible. Ces conditions sont, accrues par I'harmattan, vent chaud et sec qui souffle en permanence.

L'aridıté de la région se traduit par l'absence de cours d'eau. Seules existent des vallées fossiles, dont la plus importante, celle du Ferlo, se développe sur une longueur de $400 \mathrm{~km}$, depuis Bakel jusqu'à la zone marécageuse de Bounoum et du Lac de Guiers.

Pendant la saison des pluies de très nombreuses mares naissent tout au long de ces vallées. Certaines atteignent plusieurs hectares de superficie ef toutes se signalent par une végétation arborée beaucoup plus dense prenant parfois l'aspect de véritables fourrés. Leur vie, qu'on a vainement essayé de prolonger, ne dépasse guère quatre mois. Elles perdent leur eau dès que l'évaporation atmosphérique devient intense et laissent un fond à sol noirâtre, profondément craquelé et fissuré de toute part.

Le sous-sol offre, heureusement, au Ferlo, des réserves aquifères importantes. Elles proviennent de deux nappes différentes:
- la nappe du continent termınal, où les sables et les grès argileux domınent. Ils alternent avec des bancs d'argile dont l'épaisseur peut dépasser $130 \mathrm{~m}$. Les puits atteignent cette nappe à des profondeurs de 50 à $80 \mathrm{~m}$. Le débit est rarement supérieur à $30 \mathrm{~m}^{3}$ par jour ;

- la nappe du Maestrichtien exploitée par les forages profonds dont le débit atteint de 50 à $120 \mathrm{~m}^{3}$ par heure. Ces sables aquifères contiennent des eaux de nature différente. On distingue (5) :

- Das eaux à faciès alcalin, d'une potabılıté passable, utilisables la plupart du temps pour les besoins de la population et du cheptel, mais impropres à l'irrigation. Provenant du fleuve Sénégal, ces eaux imprègnent le sous-sol par infiltration dans les sables maestrichtiens qui affleurent sur les rives.

On y observe parfois une concentration élevée en chlorure de sodium d'orıgine géologique ou marıne. C'est ainsi que des forages à eau saumâtre se rencontrent à l'ovest de Dahra, sur la ligne Dahra-Louga.

- Des eaux à faciès alcalino-terreux, d'une potabilité convenable et excellentes pour l'irrigation. Ces equx sont d'origıne météorique et minéralisées par les terraıns sédimentaires. Le Lac de Guiers et le fleuve Sénégal en seraient la source.

\section{3o Végétation.}

La végétation est constıtuée par une savane arborée claire avec tapis de mésophytes fugaces (Schoenfeldra gracilis, Eragrostis tremula, Aristida mutabilis, Crotalaria perotteti) ef quelques graminées vivaces (Andropogon gayonus, Aristıda longiflora). Les espèces ligneuses sont soit épıneuses, soit inermes, le plus souvent à feuilles caduques et cimes non jointives (Guiero senegolensis, Combretum glutinosum, Balanites aegyptiaca, Sclerocoryo bireo) $\left(^{*}\right)$.

\section{$4^{\circ}$ Le milieu humain.}

On attribue au Ferlo une densité humaine de 0,8 habitant au $\mathrm{km}^{2}(1960)$ le chiffre est sujet à caution en raison des déplacements encore fréquents des populations.

(*) Renseignements communiqués par VALENZA J. et NAEGELE $A$. 
Les Peuls, propriétaires de la majorité des troupeaux, constituent le groupement dominant. Cependant, dans les villages de création récente, autour des forages, s'installent des communautés de cultivateurs ouolofs et des Maures, détenteurs de queiques animaux, mais dont l'activité essentielle est le commerce.

\section{C. - LES FORAGES ET LEUR INFLUENCE SUR LA VIE PASTORALE}

L'existence des grandes installations hydrauliques et leur répartition dans l'ensemble du Ferlo, constituent à l'heure actuelle, la caractéristique essentielle de cette région.

La réalisation de ces ouvrages a pu être envisagée au Sénégal à la suite de plusieurs sondages réalisés en divers points du territoire. Une série de prospections révéla l'existence d'une épaisse couche de sables aquifères, d'âge maestrichtien, reposant sur le socle granitique. Affleurants dans la région de Dakar, ces sables sont, en général, atteints à 200 ou $300 \mathrm{~m}$. Leur épaisseur est parfois considérable ( $800 \mathrm{~m}$ à Barkedji), aussi peuvent-ils être considérés comme la véritable réserve d'eau du Sénégal.

Les premiers essais eurent lieu à Kaolack en 1937 et un débil de $50 \mathrm{~m}^{3}$ heure fut Immédiatement obtenu.

En 1938, à l'initiative du Service de l'Elevage, une série de forages profonds est entreprise sur la ligne de transhumance Kaolack-Matam. Dans les années qui suivent ces ouvrages réalisés sur fonds F. I. D. E. S. se multiplient. Actuellement, une vingtaine de stations de pompage, distantes de 40 à $60 \mathrm{~km}$ peuvent être dénombrées.

Entre ces différents points des pare-feux ont été aménagés qui réalisent, ainsi, un véritable quadrillage de la région (26).

Les installations d'une unité-type comprennent : un bassin de réserve cylindrique en béton d'une capacité de $1.000 \mathrm{~m}^{3}$, une cabine abritant la pompe et le moteur d'exhaure et un petit logement pour le gardien, l'ensemble étant entouré par une clôture. A l'extérieur ont été disposés de longs abreuvorrs à niveau constant et une fontaine réservée pour la consommation humaine (photo no 1 ).

La multiplication des forages profonds a entraîné de grandes modifications du milieu, de la vie sociale et des modes d'élevage.
Comme dans toutes les zones présahariennes. l'eau est le facteur limitant du peuplement. Les. faibles possibilités offertes autrefois transformaient le Ferlo en un désert pendant une longue période de l'année. Au cours de la saison sèche les puits. rares et profonds ( 40 à $80 \mathrm{~m}$ ), ne permettaient pas l'abreuvement des troupeaux importants qui se déplaçarent alors vers des régions plus hospitalières. C'est seulement au cours de "l'hivernage » que pouvaient s'établir, dans cette région. une activité humaine et une densité animale suffisantes : les premières pluies, remettant en eau les mares abondamment réparties, amenaient le reflux des troupeaux. Une vie pastorale intense se concentrait sur leurs bords jusqu'à leur tarissement, survenant en général début novembre. Le mode d'élevage était alors dominé par la nécessité de la transhumance.

Aujourd'hui, les forages profonds offrent en abondance et en toute saison l'élément liquide indispensable. Désormais, les grands déplacements du début de saison sèche ne sont plus nécessaires : dès l'assèchement des mares les pasteurs transportent leur campement à proximité de la station hydraulique voisine. L'activité pastorale a donc maintenant tendance à devenir permanente et à s'enfermer dans les limites du Ferlo pendant toute l'année. Cette sédentarisation relative des populations et des troupeaux a une répercussion certaine sur l'équilibre du milieu naturel.

L'approche d'un forage se signale en effet, sur un rayon de plusieurs kilomètres, par la disparition progressive des herbages et de la dégradation de la flore arborée. La destruction est totale dans la périphérie immédiate de la station. Ce phénomène résulte du piétinement des troupeaux qui, chaque jour, convergent vers le lieu d'abreuvement. De même, se multiplient les ravages causés à la végétation par les feux de brousse ou des pratiques néfastes comme «l'ébranchage ». Enfin, dans certaines régions, les pâturages eux-mêmes commencent à souffrir d'une surcharge animale, bien que la fréquentation, variable d'une année à l'autre, soit difficile à apprécier. L'impression de multitude ressentie par maints observateurs aux abords des forages a conduit parfois à des surestimations.

Ces transformations du milieu naturel jouent certainement un rôle important dans l'apparition. du trouble nutritionnel et de sa complication 


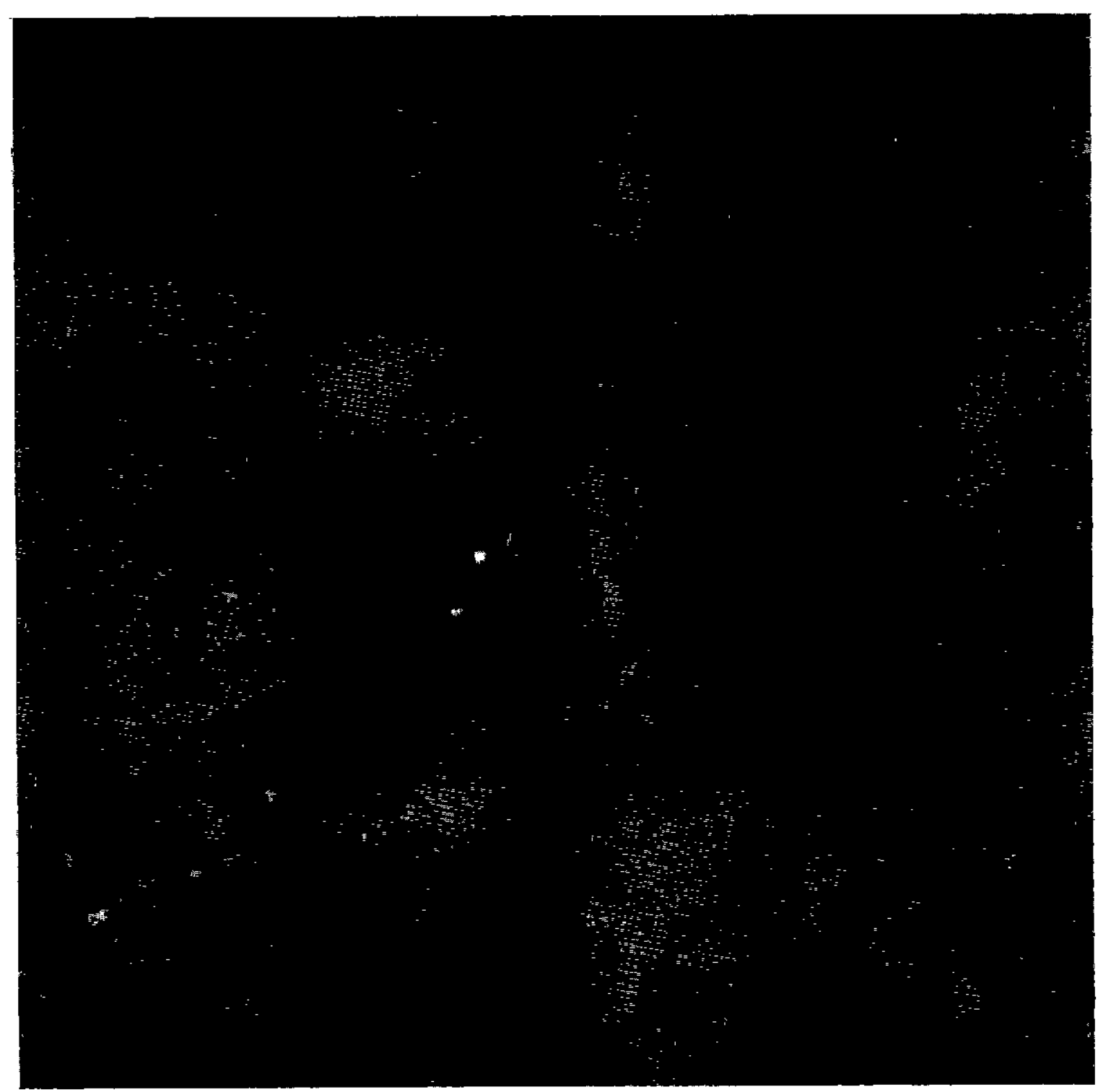

Photo $n^{0} 1$. - Vue aérienne du forage profond de Lagbar.

toxinique, causes déterminantes de ceffe affection apparue dans la région des forages du Ferlo.

\section{D. - LE GNIEDIO, MALADIE CARENTIELLE ET TOXINIQUE}

En l'absence d'une étude épidémıologıque systématique, les multiples observations rapportées de points aussi distants que Tatkı, Vélıngara et Louga, démontrent la large extension de I'affection.

D'une façon générale tout le Ferlo nord semble atteint, avec une intensité particulıère dans la zone dite «des six forages». Au sud-ouest, la maladie progresse vers Dahra ef Louga. Plus au nord, à proximité de Yang Yang ef du Lac de Guiers, les cas seraient plus rares. Les troupeaux venaient, autrefois, dans cette région, subır de véritables cures en éléments minéraux 


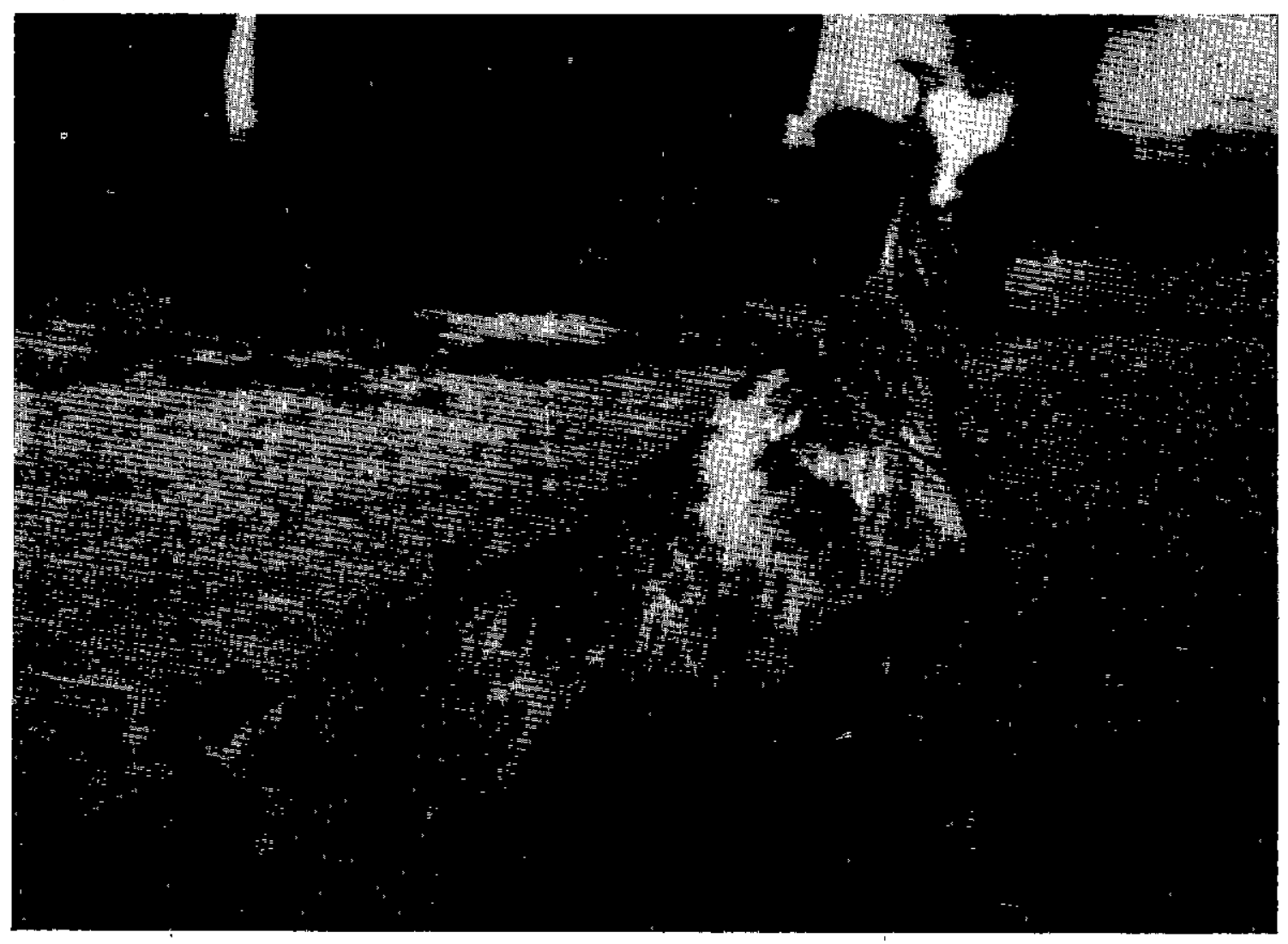

Photo $n^{0}$ 2. - Chèvre présentant une paralysie totale du train postérieur.

en absorbant les eaux salées du Lac de Guiers ou en léchant les terres natronées de Yang Yang.

L'affection ne frappe pas uniquement les zébus, elle a été rencontrée également chez l'âne, le chameau et plus rarement chez le mouton et la chèvre (photo $\left.n^{\circ} 2\right)$.

\section{Io Description clinique.}

En raison des connaissances acquises sur la pathogénie de la maladie, Il est possible de distınguer dès à présent:

10 des symptômes dus à l'aphosphorose, présents chez un grand nombre de bovins :

$2^{\circ}$ des manifestations de la toxémie botulique qui se greffent dans certaıns cas sur cet état carentiel.

Dans le premier groupe se range le pica avec une forme particulière, l'ostéophagie. Cetfe aberration est si commune que de nombreux éleveurs la considèrent comme naturelle chez leurs animaux.

Les autopsies viennent confirmer ce trouble. A l'ouverture du rumen, on découvre de gros débris osseux, des fragments de peau et des corps étrangers divers; dans la caillette, on ne trouve plus que des esquilles.

La fragilité du squelette vient compléter ce tableau clinique. Elle se traduit par de fréquentes fractures, lors de séances de vaccination par exemple.

Dans les troupeaux, où le pica est très accentué, on note, en général, un mauvais état d'entretien et surtout un plus grand nombre de pertes consécutives à des évolutions aiguès.

Les symptômes nutritionnels attirent peu l'attention des éleveurs. Pour eux, le «Gniedio» est essentiellement constitué par les manifestations de l'atteinte toxinique. 
Dans la majorité des cas l'évolution se déroule rapidement. La durée est le plus souvent de six à douze jours et, à aucun moment, on ne note d'hyperthermie. Au début on remarque une irrégularité de l'allure. L'animal offre une démarche raide, piquée, une rigidité accentuée dans la région lombaire. Pour les éleveurs, cette partıe du corps est « le siège du mal », aussi, pratiquent-ils l'application de feux en longues raies de part et d'autre de la colonne vertébrale.

Parfois un seul membre présente les signes d'une première atteinte. L'extension est difficile et le bout de l'onglon frotte le sol lors de la translation de l'extrémité distale vers l'avant.

Ces troubles fonctionnels, qui revêtent plus le caractère de parésies que de boiteries, ne s'accompagnent d'aucune déformation perceptible au niveau des rayons osseux ou des articulations. Le malade demeure en queve de troupeau puis finit par s'abattre sous un ombrage (photo $n^{0} 3$ ). Pendant quelques jours, le relevé est encore possible, puis tout effort devient vain.
La paralysie prend alors une allure ascendante pour atteindre les muscles du pharynx, de la bouche et de la langue.

La préhension des alıments, très lente, s'accompagne d'une salivation abondante. La déglutition des liquides devient impossible ef l'eau absorbée s'écoule par les naseaux. L'extériorisation manuelle de la langue s'effectue avec aisance et l'organe pend inerte sur le côté de la bouche.

Des ulcérations apparaissent au niveau du mufle; elles se couvrent de crov̂tes et de soulliures consécutives certainement à des régurgitations du rumen. Ces dernières lésıons évoquent celles observées dans le coryza gangréneux.

En phase ultime, l'animal magrit rapidement, l'œil s'enfonce, la tête devient branlante puis finalement se fléchit en position d'auto-auscultation. L'animal épuisé succombe alors en quelques jours (photo no 4).

Sur le plan biochımique, on note en général tous les indices d'une hémoconcentration avec augmentation de l'hématocrite ef du taux des

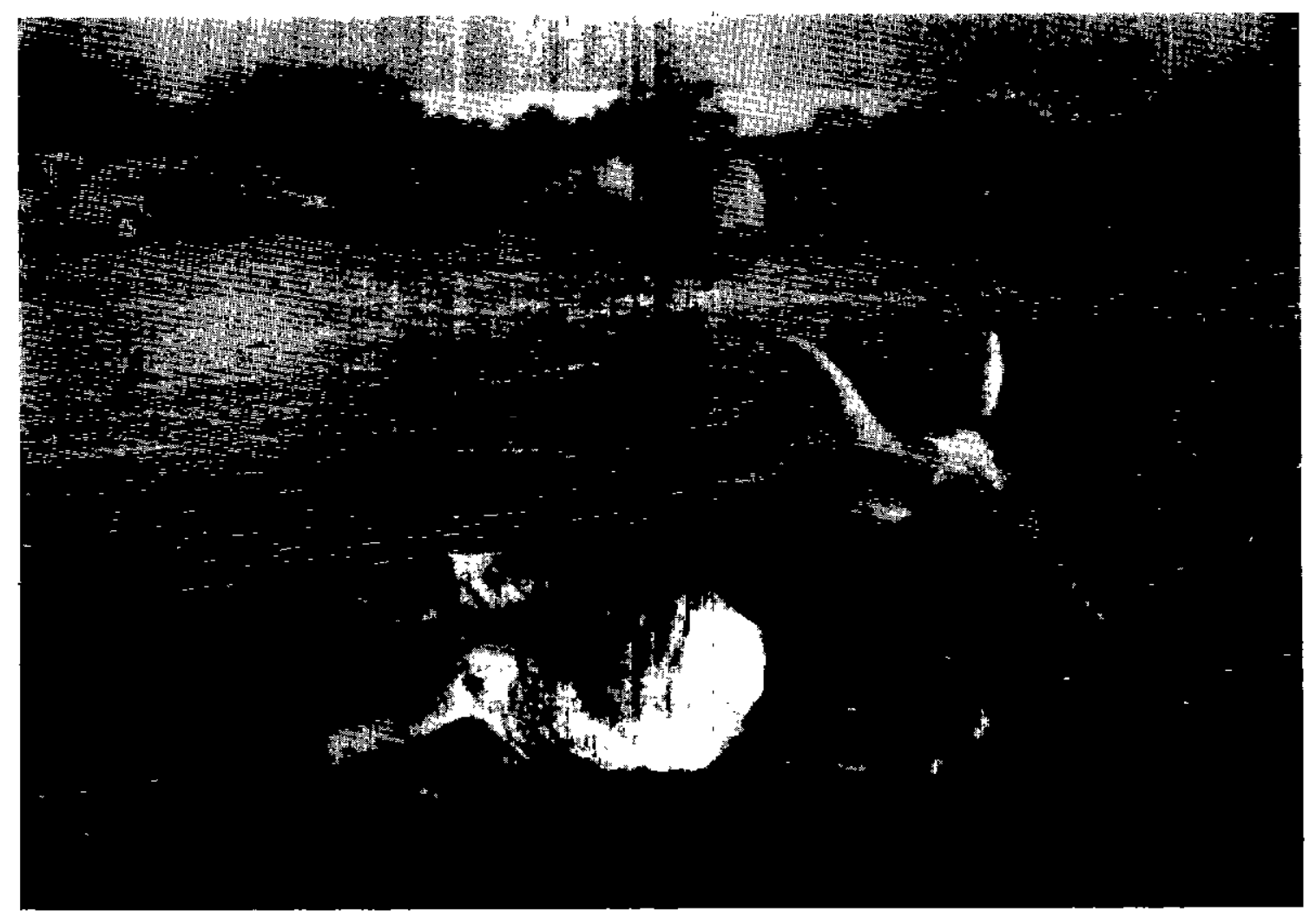

Photo $n^{\circ} 3,-$ Bovin atteint de la maladie des forages en décubitus depuis plus d'une semaıne. 


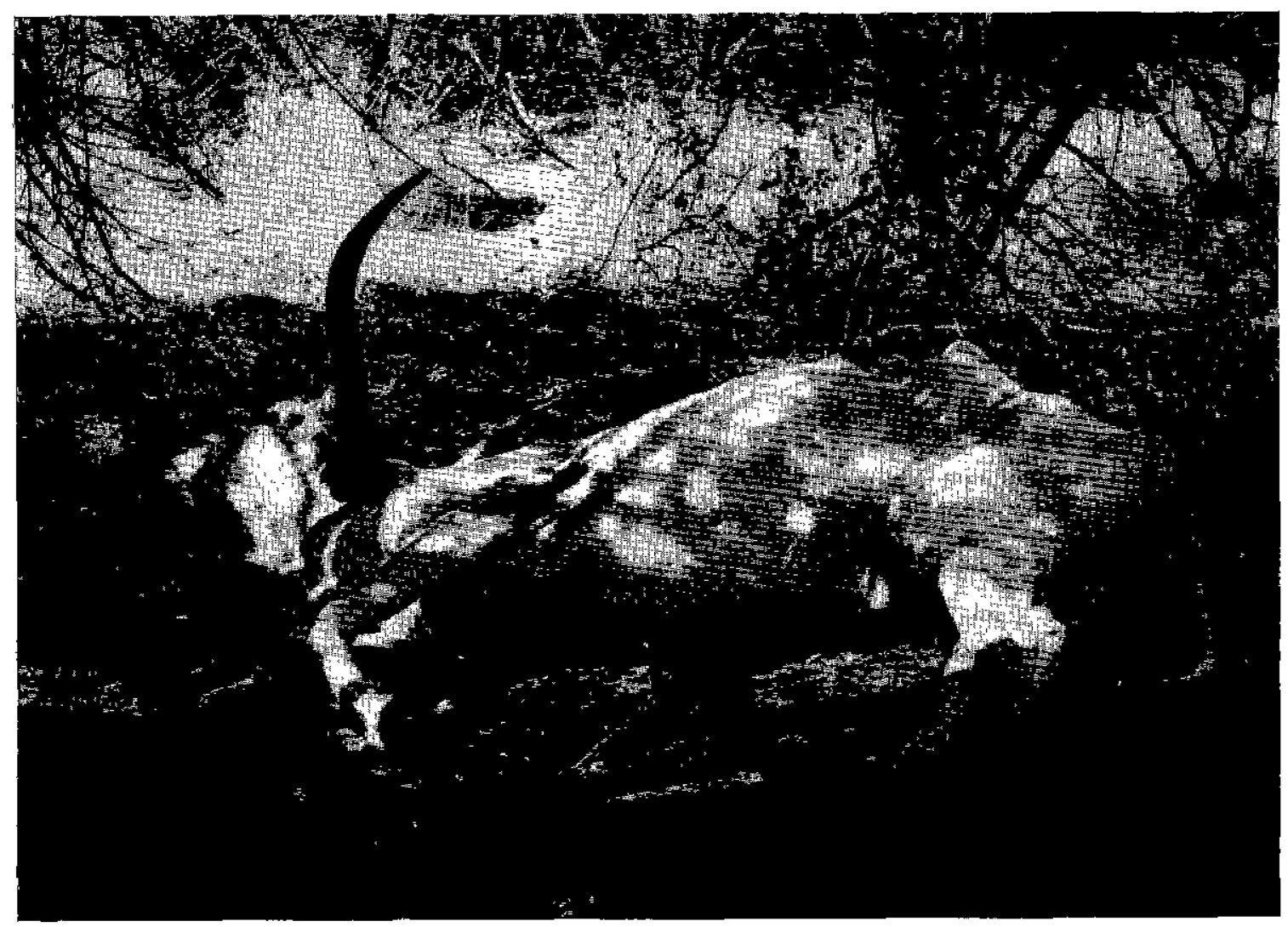

Photo no 4 - Bovin en phase terminale de la maladie.

protéines. L'urémie souvent élevée révèle un catabolisme intense. En fin d'évolution, apparaît fréquemment une hyperphosphorémie liée, peutêtre, à l'état léthargique qui s'accompagne d'une utilisation moindre des esters phosphorıques (24).

La durée des évolutions habituelles est d'environ une semaine. Parfois, s'observe une forme suraigue qui frappe des bovins généralement en bon état et à laquelle les môles seraient plus sensibles. L'incubation est alors très courte ef la mort survient sans qu'aucun symptôme ait pu attirer l'attention (43).

Dans d'autres cas, au contraire, l'atteinte semble circonscrite aux membres ef l'animal se repose fréquemment en décubitus sterno-abdominal. Cependant, il se relève pour s'alimenter et boire. Des rémissions se produisent et finalement l'individu reprend sa place au sein du troupeau. Les éleveurs prétendent que de tels sujets seront victimes presque fatalement d'une rechute l'année suivante.
Lorsque la paralysie des membres est définitive, il se peut que l'on assiste à une survie de plusieurs mois si le malade est nourri au sol. La mort est néanmoins inévitable; elle survient dans une misère physiologique complète, aggravée par de nombreuses escarres. De tels bovins sont le plus souvent sacrifiés par leur propriétaire et livrés d̀ la consommation.

\section{$2^{\circ}$ Anatomie pathologique.}

Les lésions n'ont aucun caractère spécifique. Les plus constantes se rencontrent sur l'anımal vivant, au niveau des naseaux, du mufle, des paupières et de la vulve. Ces organes sont alors le siège d'une inflammation séreuse tendant à l'ulcération. Dans d'autres cas, la muqueuse sèche, craquelée, apparaît comme brôlée.

Lors d'évolution aıgue, la peau, surtout au niveau de l'encolure, se déshydrate et se parchemine rapidement. 
Sur le cadavre on remarque souvent un piqueté hémorragique au niveau du tractus digestif. La muqueuse de la caillette semble plus fréquemment atteinte.

Dans un exemple de forme suraiguë ces lésions pétéchiales avaient pris l'allure de placards hémorragiques enveloppant une anse intestinale et débordant sur le mésentère et les ganglions lymphatiques.

Presque toujours on observe une très forte réplétion de la vésicule biliaire et de nombreux corps étrangers sont extraits du rumen. On constate couramment l'existence d'un codème pulmonaire survenu en phase agonique.

Le névraxe présente avec une certaine régularité une réduction de volume du cordon médulaire. Les méninges offrent parfois un aspect congestif surtout dans la région lombaire. L'examen histopathologique de coupes de la moelien'a révélé aucune lésion spécifique (*).

Au niveau des articulations du carpe et du tarse on observe souvent un aspect particulier du cartilage qui a attiré l'attention dès le début des recherches. II s'agit de larges érosions, à bords réguliers, au niveau desquelles le cartilage a disparu. Ces lésions ont, sans nul doute, un caractère pathologique. Cependant, fait surprenant, elles ne semblent s'accompagner que de signes fonctionnels discrets. On ne note jamais en effet, de gonflement articulaire ou synovial. D'autre part, ces altérations articulaires ne paraissent pas spécifiques «de la maladie des forages'». Elles ont été retrouvées assez régulièrement sur les os provenant d'animaux, présumés sains, abattus à Dakar. Elles sont probablement dues à un état corentiel très répandu.

\section{Etiopathogénle.}

La symptomatologie permet de dégager une pathogénie de l'affection. L'entité morbide en cause serait due à deux étiologies différentes. Les carences minérales et le botulisme, le pica, conséquence du trouble rapporté à l'hypophosphorose, permettant à l'affection toxinique de s'installer.

Tous les éleveurs sont en effet persuadés que la contagion s'effectue à partır des cadavres.

$\left.{ }^{*}\right)$ Ces résultats ont été confirmés par M. le Pr. DRIEUX.
Nous avons eu l'occasion d'observer un exemple précis très démonstratif, qui paraît présenter la valeur d'un schéma: un zébu dérobe dans une case, puis absorbe, un fragment de carcasse d'un animal abattu à la phase extrême de la maladie. Cette viande devait êtré livrée à la consommation humaine après cuisson. Dans les 10 heures qui suivent, ce bovin succombe d'une forme suraiguë du «Gniedio ».'

Les travaux de recherche ont été inspirés directement par les trois facteurs déterminants de la maladie:

carence minérale (hypophosphorose) $\rightarrow$ ostéophagie $\rightarrow$ botulisme.

Les chapitres suivants sont constitués par les observations ef les travaux effectués.

Ils ont eu pour objet de déterminer, d'abord, dans les conditions d'environnement, les facteurs favorisant l'apparition de l'affection.

En zone tropicale, en effet, l'animal, trouvant les éléments de sa subsistance uniquement dans les pâturages qu'll parcourt, est étroitement trıbutaire du milieu naturel. On est donc amené, à considérer la bıocénose formée par le sol, le végétal ef l'herbivore comme un tout, et un déséquilibre portant sur l'un des termes retenilt fatalement sur les autres.

L'exposé de ces conditions prédisposantes sera suivi des recherches plus approfondies effectuées sur l'animal en vue de déterminer, d'une part, l'origine du trouble nutritionnel et, d'autre part, la nature de la toxémie qui le complique.

\section{E. - OBSERVATIONS ET TRAVAUX DE RECHERCHES SUR LE MILIEU NATUREL}

\section{Les sols.}

La nature des sols conditionne dé façon étroıte la composition botanique et la richesse des herbages qu'ils portent.

Dans une région sèche et chaude comme le Ferlo, la différenciation essentielle se fait à partir ae la perméabilité et de la faculté plus ou moins grande à retenir l'eau. ces deux caractères étant fonction dans une large mesure de la structure physique.

Par contre, la composition chimique agit directement sur la plante et sur sa valeur fourra- 
gère. La végétation d'un sol pauvre en un élément accuse la même déficience qui se transmet ainsi aux troupeaux.

En outre, un bon équilibre entre les constituants du sol est indispensable. Le défaut de calcium ou de phosphore produit un effet aussi grave que leur absence simultanée. Un déséquilibre du rapport phospho-calcique est incompatible avec une assimilation satisfaisante de ces deux éléments minéraux.

Les divers types de sols rencontrés au Ferlo et déjà décrits, ont subi, sous l'influence des conditions climatiques, le même processus pédogénique de latérisation.

On peut alors distinguer en fonction de l'intensité des précipitations:

- dans le Ferlo nord, des sols ferrugineux tropicaux peu ou pas lessivés,

- dans le Ferlo sud, des sols ferrugineux tropıcaux lessivés (33).

Quel que soit leur stade d'évolution les analyses chimiques révèlent d'une façon générale une grande pauvreté en éléments nutritifs (tableaux nos 1, 2, 3).

Les réserves minérales sont peu importantes. Le calcium représente la fraction dominante de la somme des bases, la teneur en potassium est faible $(0,01$ à 0,05 p. 100) et celle en phosphore est nettement insuffisante. La valeur en $\mathrm{P}_{2} \mathrm{O}_{5}$ est presque toujours comprise entre 0,1 et 0,2 p. 100 . Les taux d'azote et de matières organiques, un peu plus élevés dans les sols lessivés du sud, restent toujours faibles en valeur absolve.

Du point de vue granulométrie, les sols du Ferlo sud, plus riches en éléments fins (argiles et limons) ont des réserves en eau supérieures à celles des sols du nord, à texture plus grossière.

Nous retrouvons donc, au Ferlo, une des grandes caractéristiques, soulignées dans les nombreuses études pédologiques effectuées en zone tropicale : la pauvreté en éléments nutritifs et tout particulièrement en phosphore $(32,49,50)$.

L'explication de ce phénomène réside dans l'absence d'une couche perméable, proche de la surface, susceptible d'empêcher l'entraînement des métaux et des métalloïdes par les eaux d'infiltration.

Une insuffisance analogue a été signalée sur les sols de nombreux autres pays africains : Afrique du Sud (48), Gambie (50), Rhodésie du Nord (32). En France, des zones à ostéomalacie, rapportée d̀ une carence identique en phosphore, aggravée par hypercalciose se rencontrent en Champagne, dans la Nièvre et dans certains départements du Nord.

Au Ferlo, cette déficience ne manquera pas de retentır gravement sur la santé des troupeaux. Ses répercussions sont de même nature que celles déjà signalées dans de nombreux autres pays.

\section{$2^{\circ}$ Les eaux.}

Le problème de l'eau au Ferlo et l'abreuvement des troupeaux seront étudiés en tenant compte des modalités particulières nées de la création des unités hydrauliques artificielles.

Pour la majorité des troupeaux, l'abreuvement n'est pas quotidien. Après avoir pâturé tout au long d'une journée, les bovins se rendent le lendemain au forage souvent distant d'une vingtaine de kilomètres des herbages fréquentés. Dans ces conditions, la quantité d'eau absorbée, variant suivant les estimations entre 15 et 50 litres. paraît faible. Ce fait souligne la profonde adaptation, visant à une économie de l'eau, présentée par les zébus des régions sahéliennes. Cette particularité physıologıque a faił l'objet d'études récentes chez le chameau ef les herbivores sauvages du désert. Chez ces espèces, des mécanismes propres à lutter contre la déshydratation ont été mis en évidence $(28,39)$.

De plus, aux époques des plus fortes chaleurs, les quantités absorbées ne sont guère supérieures à celles des mois frais de l'année. Cette observation contredit les nombreux travaux qui ont établi une corrélation entre la température extérieure et les besoins hydriques (27). Aux U.S.A., LEVINGSTON, PAYNE et FRIEND (37) ont montré récemment que des animoux soumis à un régime pauvre en azote sont plus aptes d̀ maintenir leur équilibre énergétique lorsque leur abreuvement est restreint. Or, les analyses de fourrages prouvent que la ration des animaux du Ferlo est, en șaison sèche, extrêmement pauvre en azote. II se peut que les bovins limitent leur absorption d'eau afin d'épargner leurs réserves azotées.

Par la composition chimique l'eau de boisson joue un rôle indirect dans la nutrition par les sels minéraux qu'elle contient. Cette modalité 
TABLEAO HOI

Composition der sols :

1\% Sols ferrugineux non lessivé, village de Diougueul-Senarabé, piste Ionofen-ieven

\begin{tabular}{|c|c|c|c|c|c|}
\hline échantillon $n^{0}$ & $26-1$ & $26-2$ & $26-3$ & $26-4$ & $26-5$ \\
\hline profondeur cm & $0-15$ & $15-30$ & $30-45$ & $45-65$ & $65-95$ \\
\hline Terre fine p.100 terre totale $\ldots \ldots \ldots \ldots \ldots$ & 0,1 & 0,2 & 0,2 & $\begin{array}{l}100 \\
0,3\end{array}$ & $\begin{array}{l}100 \\
0,3\end{array}$ \\
\hline 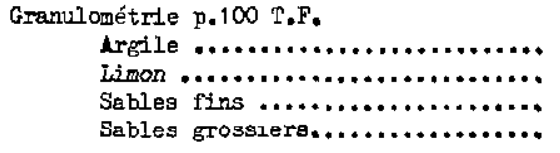 & $\begin{array}{r}2,3 \\
3,5 \\
67,1 \\
26,7\end{array}$ & $\begin{array}{r}5,0 \\
2,2 \\
66,4 \\
26,0\end{array}$ & $\begin{array}{r}6,2 \\
3,0 \\
66,4 \\
24,0\end{array}$ & $\begin{array}{r}5,0 \\
2,3 \\
62,6 \\
29,7\end{array}$ & $\begin{array}{r}4,8 \\
1,3 \\
61,1 \\
32,3\end{array}$ \\
\hline 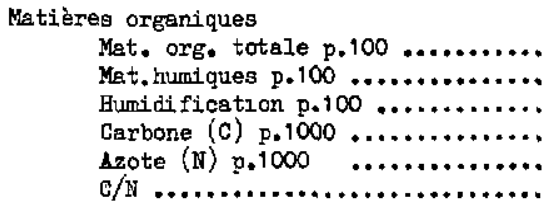 & $\begin{array}{c}0,34 \\
0,07 \\
36,0 \\
1,9 \\
0,19 \\
10,0\end{array}$ & $\begin{array}{l}0,24 \\
0,06 \\
42,9 \\
1,4 \\
0,15 \\
9,3\end{array}$ & $\begin{array}{l}0,23 \\
0,05 \\
38,5 \\
1,3 \\
0,16 \\
8,1\end{array}$ & $\begin{array}{c}0,12 \\
0,03 \\
42,9 \\
0,7 \\
0,12 \\
5,8\end{array}$ & $\begin{array}{l}0,12 \\
0,03 \\
42,9 \\
0,7 \\
0,12 \\
5,8\end{array}$ \\
\hline $\mathrm{P}_{2} \mathrm{O}_{5}$ tatal p.1000 $\ldots \ldots \ldots \ldots \ldots \ldots \ldots \ldots$ & $\underline{0,17}$ & $\underline{0,18}$ & $\underline{0.19}$ & $\underline{0.25}$ & 0.22 \\
\hline $\mathrm{F}_{2} \mathrm{O}_{3}$ libre $\mathrm{p} .000 \ldots \ldots \ldots \ldots \ldots \ldots \ldots \ldots$ & 10,13 & 10.9 & 13,5 & 12,8 & 13,1 \\
\hline $\mathrm{F}_{2} \mathrm{O}_{3}$ totel $\mathrm{p} .1000 \ldots \ldots \ldots \ldots \ldots \ldots \ldots \ldots$ & 15,1 & 14,2 & 16,1 & 14,9 & 14,4 \\
\hline $\begin{array}{l}\text { Fer libre/Fer total } \ldots \ldots \ldots \ldots \ldots \ldots \ldots \ldots \ldots \\
\text { Conpleze ebsorbant meq. } / 100 \text { g T.F. }\end{array}$ & 68 & 77 & 84 & 86 & 91 \\
\hline 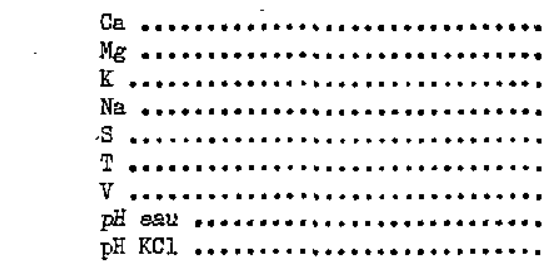 & $\begin{array}{l}0,66 \\
0,93 \\
0,03 \\
0,01 \\
1,63 \\
2,0 \\
82 \\
6,1 \\
5,1\end{array}$ & $\begin{array}{l}0,27 \\
0,66 \\
0,02 \\
0,95 \\
2,8 \\
34 \\
5,4 \\
4,3\end{array}$ & $\begin{array}{l}0,15 \\
0,72 \\
0,01 \\
0,88 \\
2,8 \\
31 \\
5,3 \\
4,2\end{array}$ & $\begin{array}{l}0,12 \\
0,72 \\
0,01 \\
0,85 \\
2,6 \\
33 \\
5,3 \\
4,3\end{array}$ & $\begin{array}{l}0,49 \\
0,52 \\
0,02 \\
1,03 \\
2,9 \\
36 \\
5,2 \\
4,1\end{array}$ \\
\hline Porosité sur mottes p.100 & & & r & & \\
\hline $\begin{array}{l}\text { Eumidité équivalente p.100 } \ldots \ldots \ldots \ldots \ldots \ldots \\
\text { Pount de flétrissement } \ldots \ldots \ldots \ldots \ldots \ldots \ldots \ldots \\
\text { Eau utile p.100 } \ldots \ldots \ldots \ldots \ldots \ldots \ldots \ldots \ldots \ldots \\
\text { Structure }\end{array}$ & $\begin{array}{l}2,0 \\
1,2 \\
0,8\end{array}$ & $\begin{array}{l}2,5 \\
1,7 \\
0,8\end{array}$ & $\begin{array}{l}2,9 \\
2,2 \\
0,7\end{array}$ & $\begin{array}{l}3,4 \\
2,6 \\
0,8\end{array}$ & $\begin{array}{l}3,3 \\
2,5 \\
0,8\end{array}$ \\
\hline $\begin{array}{l}\text { Taux d'agt. alcool } p_{*} 100 \ldots \ldots \ldots \ldots \\
\operatorname{taux} d{ }^{\prime} a g t, \text { equ } p_{.} 100 \ldots \ldots \ldots \ldots \ldots \\
\text { taux d'agr. benzène } \ldots \ldots \ldots \ldots \ldots\end{array}$ & $\begin{array}{l}29,4 \\
29,8 \\
29,5\end{array}$ & $\begin{array}{l}32,1 \\
28,7 \\
28,2\end{array}$ & $\begin{array}{l}29,3 \\
28,9 \\
20,6\end{array}$ & & \\
\hline Perméabilité $\mathrm{x} \mathrm{cm} / \mathrm{h} \ldots \ldots \ldots \ldots \ldots \ldots \ldots \ldots$ & 2,7 & 2,0 & 4,7 & & \\
\hline
\end{tabular}

(*) Extraits de "Reconnaigsance pédologique du Ferlo Sud "O.R.S.T.O.H. avril 1964

d'apport est particulièrement importante dans le métabolisme phospho-calcique. Un exçès de minéralisation comme une insuffisance influencent l'équilibre physiologique. On connaît des troubles digestifs qui surviennent après la consommation abondante d'une eau saumâtre et le manque d'iode ou de calcium compromet l'élevage dans certaines régions."

L'élément liquide dissout les sels minéraux contenus dans les sols; on peut donc prévoir que les eaux du Ferlo constitueront, pour le cheptel, un apport en éléments minéraux de faible valeur.

Les forages profonds, devenus la source d'abreuvement des troupeaux pendant 7 mois de l'année, exploitent des nappes de composition différente qui donnent soit des equx calciques, soit des eaux sodiques (carte III). 


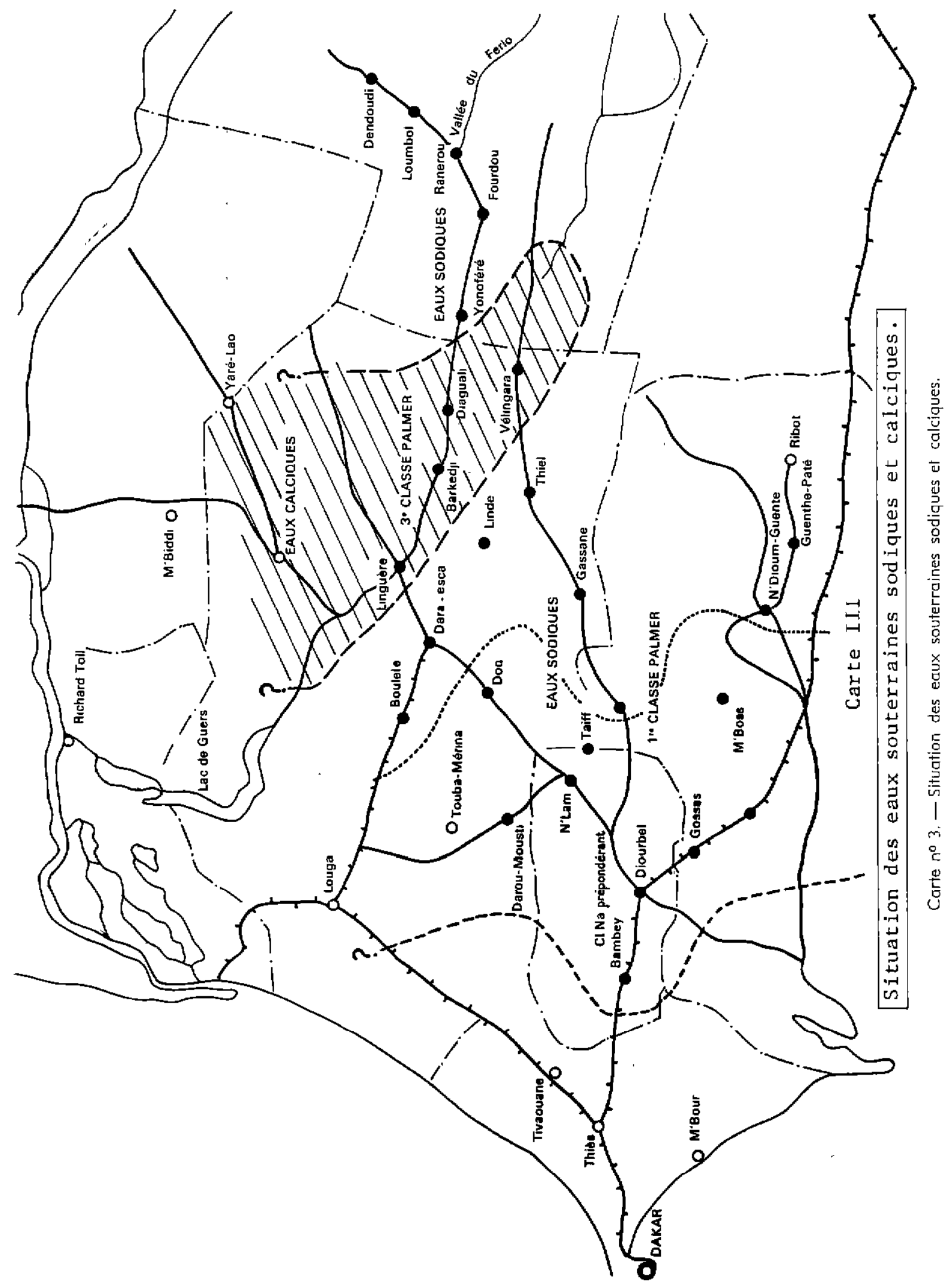


TABLEAD NOII

Composition des sols (suite)

2\%/ Sols ferruzineux lessivés,village de Bantangueu, piste Koussanar-Daoudi

\begin{tabular}{|c|c|c|c|c|c|c|c|}
\hline Echantillon $\mathrm{n}^{\circ}$ & $1-1$ & $1-2$ & $1-3$ & $1-4$ & $1-5$ & $1-6$ & $1-7$ \\
\hline profondeur & $0-20$ & $20-35$ & $35-55$ & $55-100$ & $100-125$ & $125-150$ & 150 \\
\hline $\begin{array}{l}\text { Terre fine p.100 terre totale } \\
\text { Humidité p.100 T.F. .......... }\end{array}$ & $\begin{array}{l}100 \\
0,2\end{array}$ & $\begin{array}{l}100 \\
0,4\end{array}$ & 100 & $\begin{array}{l}100 \\
0,6\end{array}$ & $\begin{array}{l}100 \\
0,3\end{array}$ & $\begin{array}{l}100 \\
0.5\end{array}$ & 100 \\
\hline 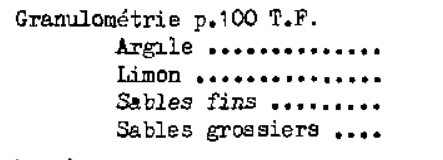 & $\begin{array}{r}6,3 \\
3,0 \\
32,1 \\
58,0\end{array}$ & $\begin{array}{r}11,1 \\
2,0 \\
35,4 \\
50,7\end{array}$ & $\begin{array}{r}13,9 \\
2,5 \\
35,9 \\
47,0\end{array}$ & $\begin{array}{r}19,9 \\
3,2 \\
27,9 \\
48,2\end{array}$ & $\begin{array}{r}22,4 \\
2,0 \\
24,5 \\
50,6\end{array}$ & $\begin{array}{r}23,8 \\
2,5 \\
26,6 \\
46,6\end{array}$ & $\begin{array}{r}23,0 \\
2,8 \\
26,3 \\
47,2\end{array}$ \\
\hline 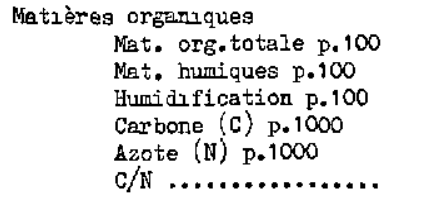 & $\begin{array}{l}0,44 \\
0,09 \\
34,6 \\
2,6 \\
0,37 \\
7,0\end{array}$ & $\begin{array}{l}0,36 \\
0,07 \\
33,3 \\
2,1 \\
0,30 \\
7,0\end{array}$ & $\begin{array}{l}0,33 \\
0,06 \\
31,6 \\
1,9 \\
0,29 \\
6,6\end{array}$ & $\begin{array}{l}0,21 \\
0,04 \\
33,3 \\
1,2 \\
0,19 \\
6,3\end{array}$ & $\begin{array}{c}0,20 \\
0,03 \\
25,0 \\
1,2 \\
0,16 \\
6,7\end{array}$ & ' & \\
\hline$P_{2} O_{5}$ total p.1000 $\ldots \ldots \ldots \ldots$ & 0,11 & 0,15 & 0,15 & 0,16 & 0,12 & 0,21 & 0,13 \\
\hline${ }_{2} \mathrm{O}_{3}$ libre $p_{.1000} \ldots \ldots \ldots \ldots$ & 8,7 & 9.9 & 12,3 & 16,3 & 16,7 & 16.7 & 17.9 \\
\hline$F_{2} O_{3}$ total p.1000 $\ldots \ldots \ldots \ldots$ & 12,5 & 14.4 & 16,8 & 20,4 & 22,3 & 22,1 & 22,8 \\
\hline Fex libre/Fer total .......... & 70 & 69 & 73 & 80 & 75 & 76 & 79 \\
\hline 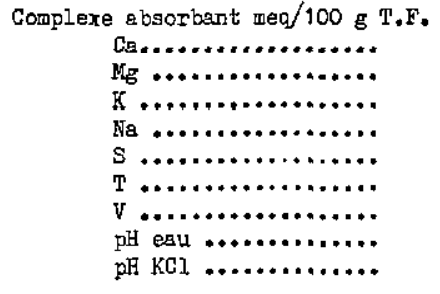 & $\begin{array}{l}1,02 \\
0,38 \\
0,04 \\
0,07 \\
1,57 \\
1,6 \\
94 \\
6,1 \\
5,1\end{array}$ & $\begin{array}{l}0,94 \\
0,36 \\
0,03 \\
0,04 \\
1,37 \\
1,7 \\
81 \\
5,9 \\
4,9\end{array}$ & $\begin{array}{l}0,86 \\
0,72 \\
0,04 \\
0,04 \\
1,66 \\
2,1 \\
79 \\
6,0 \\
4,9\end{array}$ & $\begin{array}{c}0,90 \\
0,82 \\
0,04 \\
0,06 \\
1,82 \\
2,2 \\
83 \\
6,0 \\
4,9\end{array}$ & $\begin{array}{l}0,81 \\
1,26 \\
0,03 \\
0,07 \\
2,17 \\
2,5 \\
87 \\
6,2 \\
5,2\end{array}$ & $\begin{array}{l}0,83 \\
1,02 \\
0,05 \\
0,06 \\
1,98 \\
2,8 \\
71 \\
6,0 \\
5,0\end{array}$ & $\begin{array}{l}0,89 \\
1,00 \\
0,03 \\
0,06 \\
1,98 \\
2,7 \\
73 \\
5,8 \\
4,8\end{array}$ \\
\hline $\begin{array}{l}\text { Porosité sur wottes p.1000 } \\
\text { Humidi té équivalente p.1000 } \\
\text { Point de flétrissement p.100 } \\
\text { Eav utile p.100 } \ldots \ldots \ldots \ldots \ldots . .\end{array}$ & $\begin{array}{r}37,3 \\
, 2 \\
2,2 \\
1,0\end{array}$ & $\begin{array}{r}35,4 \\
3,9 \\
2,8 \\
1,1\end{array}$ & $\begin{array}{r}36,7 \\
4,6 \\
3,7 \\
0,9\end{array}$ & $\begin{array}{r}30,2 \\
6,3 \\
5,1 \\
1,2\end{array}$ & $\begin{array}{l}8,0 \\
6,3 \\
1,7\end{array}$ & $\begin{array}{l}8,0 \\
6,1 \\
1,9\end{array}$ & $\begin{array}{l}7,6 \\
5,8 \\
1,8\end{array}$ \\
\hline $\begin{array}{l}\text { Structure } \\
\text { taux d'agr. alcool p.100 } \\
\text { taus d'agr. eau p. } 100 \\
\text { taux d'agr. benzene. }\end{array}$ & $\begin{array}{l}54,0 \\
35,7 \\
57,3\end{array}$ & $\begin{array}{l}53,0 \\
57,6 \\
50.9\end{array}$ & $\begin{array}{l}56,6 \\
56,6 \\
51,7\end{array}$ & & & i & \\
\hline $\begin{array}{l}\text { Perwéabilzté } \mathrm{K} \mathrm{cm} / \mathrm{b} \ldots \ldots \ldots \ldots \\
\text { Instabr.lité str. I.S. ........... }\end{array}$ & $\begin{array}{l}1,7 \\
1,17\end{array}$ & $\begin{array}{l}1,9 \\
1,04\end{array}$ & $\begin{array}{l}3,5 \\
1,23\end{array}$ & 3.9 & 3,4 & 2,9 & 2,8 \\
\hline
\end{tabular}

Quelle que soit la nature des ions rencontrés, le taux de minéralisation reste faible variant entre 0,1 et $0,15 \mathrm{~g}$ par litre de résidu sec. Quant à la composition chımique des eaux de mares utilisées par les troupeaux pendant les mois d'hivernage, elle nous est à l'heure actuelle inconnue (tableaux $4,5,6,7$ ).

Tout au plus peut-on dire qu'elles sont d'un aspect peu engageant. Troublés par le plétinement, souillés par l'urine et les excréments, ces lieux d'abreuvement ne semblent guère hygiéniques. Mais il se peut que l'abondance des déchets organiques ef la pullulation de la microflore fournissent une source d'éléments nutritifs non négligeables.

Dernièrement, ont été mises en évidence (B. R. G. M. Dakar) des bactéries capables de concentrer les métaux, l'or en particulier. II n'est donc pas impossible d'envisager que certains micro-organismes contenus dans l'eau des mares, puissent jover le même rôle vis-à-vis du phosphore.

Concernant la «maladie des forages》, quels éléments favorisants peut-on tirer de ces diverses données?

La carte situant la répartition des eaux souter- 


\section{TABLEAU NOII}

COMPOSITION DES SOLS (sute)

30/ Sols hydromorphes

village de Maka, piste Sare Moude et M'Bouro

Frofil 21

Protil 27

\begin{tabular}{|c|c|c|c|c|c|c|c|}
\hline échantillon $n^{\circ}$ & $21-1$ & $21-2$ & $21-4$ & $37-1$ & $37-2$ & $37-3$ & $37-5$ \\
\hline profondeur en cm & $0-15$ & $15-45$ & $45-75$ & $75-110$ & $0-5$ & $5-15$ & $45-70$ \\
\hline $\begin{array}{l}\text { Terre fine p.100 terre totale } \ldots \ldots \ldots \ldots . \\
\text { Eumidnté p.100 .......................... } \\
\text { Granulométrie p.100 T.F. }\end{array}$ & $\begin{array}{l}100 \\
0,7\end{array}$ & $\begin{array}{l}10 \mathrm{C} \\
2,4\end{array}$ & $\begin{array}{r}100 \\
4,0\end{array}$ & $\begin{array}{l}100 \\
1,4\end{array}$ & $\begin{array}{c}100 \\
0,3\end{array}$ & 100 & $\begin{array}{l}100 \\
0,4\end{array}$ \\
\hline $\begin{array}{l}\text { Argile } \ldots \ldots \ldots \ldots \ldots \ldots \ldots \ldots \ldots \ldots \\
\text { Limon } \ldots \ldots \ldots \ldots \ldots \ldots \ldots \ldots \ldots \\
\text { Sables fins } \ldots \ldots \ldots \ldots \ldots \ldots \ldots \ldots \\
\text { Sables grossiers } \ldots \ldots \ldots \ldots \ldots \ldots\end{array}$ & $\begin{array}{l}15,5 \\
11,0 \\
57,3 \\
14,8\end{array}$ & $\begin{array}{r}35,5 \\
4,3 \\
44,9 \\
12,5\end{array}$ & $\begin{array}{r}47,2 \\
2,7 \\
34,4 \\
11,5\end{array}$ & $\begin{array}{r}43,2 \\
6,3 \\
37,6 \\
11,3\end{array}$ & $\begin{array}{r}11,7 \\
4,1 \\
69,9 \\
12,4\end{array}$ & $\begin{array}{r}12,8 \\
9,6 \\
61,1 \\
17,7\end{array}$ & $\begin{array}{r}13,1 \\
6,7 \\
69,9 \\
12,8\end{array}$ \\
\hline 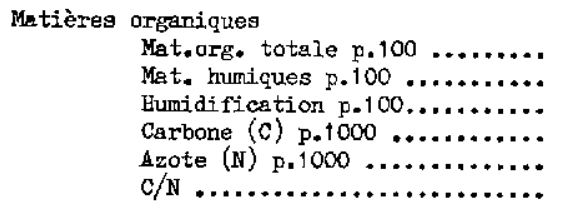 & $\begin{array}{c}0,67 \\
0,11 \\
22,2 \\
3,9 \\
0,30 \\
13,0\end{array}$ & $\begin{array}{l}0,41 \\
0,09 \\
37, \overline{3} \\
2,4 \\
0,26 \\
9,2\end{array}$ & $\begin{array}{l}0,20 \\
0,02 \\
16,7 \\
1,2 \\
0,22 \\
5,5\end{array}$ & $\begin{array}{l}0,17 \\
0,02 \\
20,0 \\
1,0 \\
0,15 \\
6,7\end{array}$ & $\begin{array}{c}1,61 \\
0,21 \\
21,2 \\
0,9 \\
0,67 \\
14,9\end{array}$ & $\begin{array}{c}1,31 \\
0,20 \\
26,3 \\
7,6 \\
0,55 \\
13,8\end{array}$ & $\begin{array}{c}0,16 \\
0,04 \\
44,4 \\
0,9 \\
0,13 \\
6,09\end{array}$ \\
\hline$P_{2} \mathrm{O}_{5}$ total $p .1000 \ldots \ldots \ldots \ldots \ldots \ldots \ldots \ldots$ & 0,14 & 0,14 & 0,18 & 0,17 & & 0,21 & 0,11 \\
\hline $\mathrm{F}_{2} \mathrm{O}_{3}$ libre $\mathrm{p} .1000 \ldots \ldots \ldots \ldots \ldots \ldots \ldots \ldots \ldots \ldots \ldots$ & 12,2 & 23,1 & 24,3 & 27,9 & 4,8 & 4,8 & 3,9 \\
\hline $\mathrm{F}_{2} \mathrm{O}_{3}$ total $\mathrm{p} \cdot 1000 \ldots \ldots \ldots \ldots \ldots \ldots \ldots \ldots$ & 15,6 & 29,1 & 34,6 & 34,4 & 8,2 & 7.5 & 6,7 \\
\hline $\begin{array}{l}\text { Fer libre } / \text { Fer total } \ldots \ldots \ldots \ldots \ldots \ldots \ldots \ldots \\
\text { Compleze absorbent meq } / 100 \mathrm{~g} \text { T.F. }\end{array}$ & 78 & 49 & 70 & 81 & 59 & 64 & 58 \\
\hline 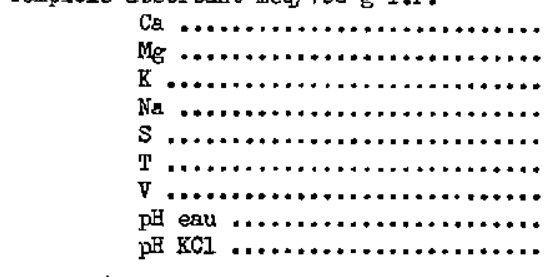 & $\begin{array}{l}1,47 \\
1,44 \\
0,05 \\
0,16 \\
3,12 \\
4,5 \\
69 \\
5,9 \\
4,9\end{array}$ & $\begin{array}{l}3,63 \\
2,20 \\
0,07 \\
0,34 \\
6,24 \\
8,1 \\
77 \\
5,6 \\
4,5\end{array}$ & $\begin{array}{l}6,30 \\
3,29 \\
0,07 \\
0,64 \\
10,30 \\
11,8 \\
87 \\
5,4 \\
4,5\end{array}$ & $\begin{array}{l}7,32 \\
3,26 \\
0,07 \\
0,76 \\
11,41 \\
11,6 \\
98 \\
7,3 \\
6,3\end{array}$ & $\begin{array}{l}4,58 \\
1,05 \\
0,08 \\
0,10 \\
5,01 \\
6,3 \\
92 \\
6,7 \\
5,8\end{array}$ & $\begin{array}{l}2,86 \\
1,66 \\
0,06 \\
0,12 \\
4,70 \\
5,2 \\
90 \\
6,5 \\
5,7\end{array}$ & $\begin{array}{c}1,21 \\
0,65 \\
0,03 \\
0,07 \\
1,96 \\
2,4 \\
82 \\
5,8 \\
4,7\end{array}$ \\
\hline 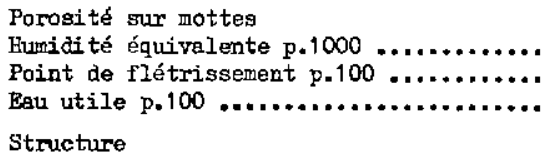 & $\begin{array}{r}11.9 \\
4.1 \\
7.8\end{array}$ & $\begin{array}{r}15,2 \\
9,0 \\
6,2\end{array}$ & $\begin{array}{r}17,3 \\
13,0 \\
4,3\end{array}$ & $\begin{array}{c}18,01 \\
12,2 \\
5,8\end{array}$ & $\begin{array}{l}7,2 \\
3,2 \\
4,0\end{array}$ & $\begin{array}{l}6,3 \\
2,8 \\
3,5\end{array}$ & $\begin{array}{l}5,0 \\
2,7 \\
2,3\end{array}$ \\
\hline $\begin{array}{l}\text { Taux d'agr. alcool p.100 } \\
\text { Taux d'agr. eau p. } 100 \ldots \ldots \ldots \ldots \\
\text { Taux d'agr. benzène } \ldots \ldots \ldots \ldots\end{array}$ & $\begin{array}{l}22,8 \\
20,2 \\
18,2\end{array}$ & $\begin{array}{l}31,6 \\
18,4 \\
14,4\end{array}$ & $\begin{array}{l}33,2 \\
23,9 \\
12,4\end{array}$ & & $\begin{array}{l}28,2 \\
25,9 \\
23,7\end{array}$ & $\begin{array}{l}31,8 \\
27,0 \\
20,1\end{array}$ & $\begin{array}{l}14,3 \\
12,5 \\
12,3\end{array}$ \\
\hline 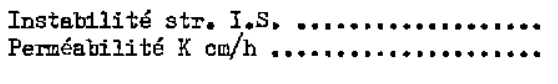 & $\begin{array}{l}3,73 \\
0,4\end{array}$ & $\begin{array}{l}4,43 \\
0,9\end{array}$ & $\begin{array}{l}4,34 \\
0,5\end{array}$ & & $\begin{array}{l}0,70 \\
2,5\end{array}$ & $\begin{array}{l}0,67 \\
2,3\end{array}$ & $\begin{array}{l}4,65 \\
1,5\end{array}$ \\
\hline
\end{tabular}

raines fournıt d'abord une indication intéressante. En effet, la zone des eaux à faciès alcalino-terreux correspond au Ferlo nord où l'affection présente lä pius forte endémicité. II ne fait alors pas de doute que le supplément de calcium apporté par ces eaux contribue à l'aggravation du déséquilibre phospho-calcique dont souffrent les animaux.

D'autre part, les fatıgues causées par- les longues marches pour se rendre au forage accentuent encore le caractère de dure épreuve que constituent pour les troupeaux les derniers mois de la saison sèche au Ferio. L'organısme animal mobilise alors tous les mécanismes physiologiques, restreint son abreuvement pour survivre jusqu'aux premières pluies. Durant cette période il est évidemment plus réceptif à toutes les maladies. 
TLBLELO HO IT

inelyse d'ean de forage (B.R.G.H.)

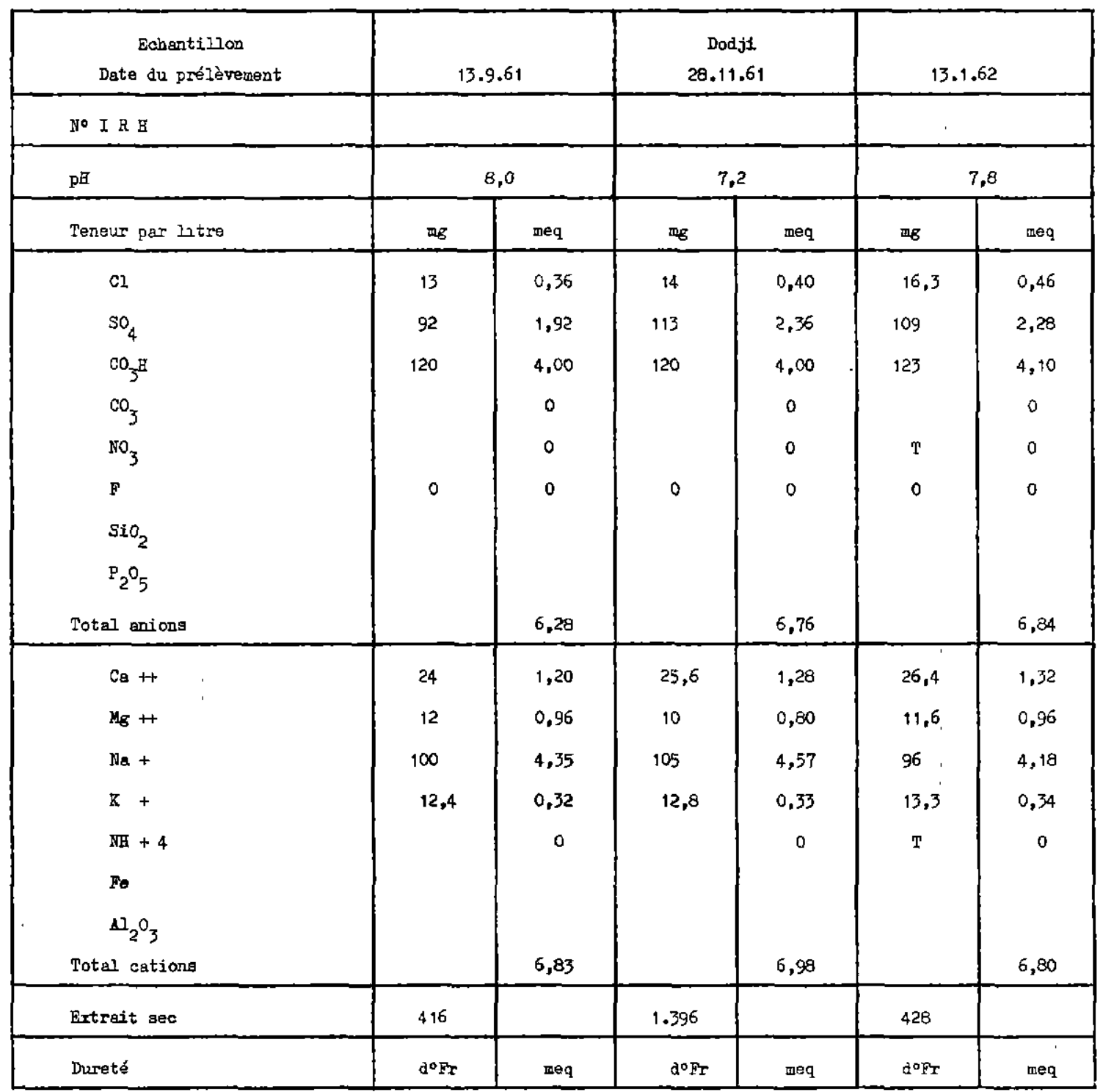

\section{Les fourrages.}

Une richesse relative en espèces fourragères confère à la zone sahélienne une vocation pastorale. L'herbe et l'arbre s'y trouvent associés et si les légumineuses et les graminées représentent les aliments de base des herbivores, la végétation arborée constitue un appoint important en saison sèche. Gousses, feuilles et fruits divers permettent aux animaux de franchir des périodes difficiles.
Les productions des «cades» (Faidherbia albida), des «seings》 (Acacia fortilis), des «sourous》 (Acacia seyal), des «beurs» (Poupartia) et des « rands » (Baubrinia rufescens) sont particulièrement appréciées. La quantité de feuilles et de débris végétaux qui jonchent le sol, après le passage d'un feu de brousse, et que consomment les ruminants mérite d'être soulignée. En 1955, dans la région de Lagbar, ADAM a pu l'estimer à plus de $870 \mathrm{~kg}$ à l'hectare (22). Leur valeur 
TABLASD $F^{\circ} \mathrm{V}$

inalyse d'eau de forage (B.R.G.M.) (suite)

\begin{tabular}{|c|c|c|c|c|c|c|c|c|}
\hline $\begin{array}{l}\text { Echantillan } \\
\text { Date du prélarement }\end{array}$ & \multicolumn{2}{|c|}{15.9 .61} & \multicolumn{2}{|c|}{$\begin{array}{l}\text { Yare - Lao } \\
28.11 .61\end{array}$} & \multicolumn{2}{|c|}{8.3 .62} & \multicolumn{2}{|c|}{14.1 .62} \\
\hline \multicolumn{9}{|l|}{ No I A म } \\
\hline $\mathrm{pH}$ & \multicolumn{2}{|c|}{8,0} & \multicolumn{2}{|c|}{7,4} & \multicolumn{2}{|c|}{7,6} & \multicolumn{2}{|c|}{2,8} \\
\hline Teneur par litre & mg & meq & 吗 & meq & mg & meq & $\mathbb{m g}$ & meq \\
\hline $\begin{array}{c}\mathrm{Cl} \\
\mathrm{SO}_{4} \\
\mathrm{CO}_{3} \mathrm{H} \\
\mathrm{CO}_{3} \\
\mathrm{NO}_{3} \\
\mathrm{~F} \\
\mathrm{SiO}_{2} \\
\mathrm{P}_{2} \mathrm{O}_{5}\end{array}$ & $\begin{array}{c}21 \\
4,8 \\
126 \\
\\
9 \\
0,4\end{array}$ & $\begin{array}{c}0,60 \\
0,10 \\
4,20 \\
0 \\
0 \\
0,02\end{array}$ & $\begin{array}{l}21 \\
12 \\
12,6 \\
0\end{array}$ & $\begin{array}{c}0,60 \\
0,24 \\
4,20 \\
0 \\
0 \\
0\end{array}$ & $\begin{array}{c}22,7 \\
40,3 \\
118 \\
T\end{array}$ & $\begin{array}{c}0,64 \\
0,84 \\
3,95 \\
0 \\
0 \\
0\end{array}$ & $\begin{array}{c}21,3 \\
24 \\
121 \\
2 \\
T\end{array}$ & $\begin{array}{c}0,60 \\
0,50 \\
4,05 \\
0 \\
0,03 \\
0 \\
\\
\\
5,18\end{array}$ \\
\hline $\begin{array}{c}\mathrm{Ca}++ \\
\mathrm{Mg}++ \\
\mathrm{Na}+ \\
\mathrm{K}+ \\
\mathrm{NH}+4 \\
\mathrm{Fe} \\
\mathrm{Al}_{2} \mathrm{O}_{3} \\
\text { Totel cations }\end{array}$ & $\begin{array}{l}24 \\
14,5 \\
59,5 \\
12 \\
0\end{array}$ & $\begin{array}{l}1,20 \\
1,20 \\
2,50 \\
0,31\end{array}$ & $\begin{array}{l}25,6 \\
15,5 \\
57,5 \\
11,1\end{array}$ & $\begin{array}{l}1,28 \\
1,28 \\
2,50 \\
0,28\end{array}$ & $\begin{array}{l}22,4 \\
16,5 \\
66 \\
12,0\end{array}$ & $\begin{array}{l}1,12 \\
1,36 \\
2,87 \\
0,31\end{array}$ & $\begin{array}{l}24 \\
15,7 \\
59 \\
11,2\end{array}$ & $\begin{array}{c}1,20 \\
1,30 \\
2,57 \\
0,29 \\
0\end{array}$ \\
\hline Extrait sec & 276 & & 468 & & 288 & & 344 & \\
\hline Dureté & $d^{d} F_{T}$ & meq & $\mathrm{d}^{\mathrm{a}} \mathrm{FT}$ & meq & $d^{\circ} \mathrm{Fr}$ & meq & $\mathrm{d} \cap \mathrm{Fr}$ & meq \\
\hline
\end{tabular}

alımentaire ressortant, telle qu'elle résulte des analyses chimiques (MAINGUY, 1955), équivaudrait à celle des pailles fourragères.

En outre, les bergers attribuent parfois des vertus thérapeutiques aux branchages donnés en vert aux bovins. Cette conception et la pauvreté des pâturages expliquent la pratique de l'émondage qui contribue à la destruction de la végétation au Ferlo.

Des études très complètes sur cette région du Sénégal concernant le problème botanique des groupements végétaux et de leur inventaire floristique ont été réalisées et publiées dans les ouvrages de TROCHAIN (46), de ROBERTY (36) ef dans les publications de MAINGUY ef RAYNAL (35).

Depuis l'implantation des forages profonds la presque totalité des surfaces pâturables peut être exploitée. Sur la carte il serait possible de représenter une succession « d'unịtés d'élevage » centrées par une installation hydraulique. A l'intérieur de ces aires la répartition des troupeaux n'est pas homogène. Les campements ont tendance à se concentrer dans une zone circulaire située à une distance de 6 à $12 \mathrm{~km}$ du forage. Plus près, les pâturages sont dégradés par le piétınement des troupeaux, au-delà, ils imposent aux zébus des marches trop longues pour se rendre à l'abreuvoir. Il en résulte que dans cette zone d'implantation favorable, if existe souvent une charge animale excessive conduisant à la malnutrition ef à l'appauvrissement progressif des herbages.

La valeur nutritive des fourrages se déduit de leur analyse chimique. De nombreux échantillonnages ont été effectués, soit au cours de missions d'études botaniques, soit lors des recherches sur «la maladie des forages». Cer- 
TLBLEAO NOVI

inalyse d'ean de forage (B.R.G.M.) (suite)

\begin{tabular}{|c|c|c|c|c|c|c|c|c|}
\hline $\begin{array}{c}\text { Echantillon } \\
\text { Date du prélèvement }\end{array}$ & \multicolumn{2}{|c|}{14.9 .61} & \multicolumn{2}{|c|}{$\begin{array}{l}\text { Linguere } \\
27.11 .61\end{array}$} & \multicolumn{2}{|c|}{8.3 .62} & \multicolumn{2}{|c|}{11.1 .62} \\
\hline$N^{0}$ I R $\mathrm{B}$ & & & & & & & & \\
\hline $\mathrm{pH}$ & \multicolumn{2}{|c|}{7,6} & \multicolumn{2}{|c|}{7,5} & \multicolumn{2}{|c|}{7,6} & \multicolumn{2}{|c|}{7,5} \\
\hline Teneur par litre & ng & meq & mg & meq & ug & meq & mg & meq \\
\hline $\begin{array}{c}\mathrm{Cl} \\
\mathrm{SO}_{4} \\
\mathrm{CO}_{3} \mathrm{~B} \\
\mathrm{CO}_{3} \\
\mathrm{NO}_{3} \\
\mathrm{~F}^{2} \\
\mathrm{SiO}_{2} \\
\mathrm{P}_{2} \mathrm{O}_{5} \\
\text { Total anions }\end{array}$ & $\begin{array}{l}35.5 \\
280 \\
120\end{array}$ & $\begin{array}{c}1,00 \\
5,84 \\
4,00 \\
0 \\
0 \\
0\end{array}$ & $\begin{array}{l}35,5 \\
336 \\
126\end{array}$ & $\begin{array}{l}1 \\
7,00 \\
4,20 \\
0 \\
0 \\
0,02\end{array}$ & $\begin{array}{r}39 \\
288 \\
118 \\
\\
2 \\
T\end{array}$ & $\begin{array}{c}1,10 \\
6,00 \\
3,95 \\
0 \\
0,03 \\
0\end{array}$ & $\begin{array}{l}42,6 \\
312 \\
123\end{array}$ & $\begin{array}{c}1,20 \\
6,50 \\
4,10 \\
0 \\
0 \\
0\end{array}$ \\
\hline $\begin{array}{l}\mathrm{Ca}++ \\
\mathrm{Mg}+ \\
\mathrm{Na}+ \\
\mathrm{K}+ \\
\mathrm{NH}+4 \\
\mathrm{Fe} \\
\mathrm{Al}_{2} \mathrm{O}_{3} \\
\text { Total cationg }\end{array}$ & $\begin{array}{l}53,8 \\
20 \\
155 \\
16,5\end{array}$ & $\begin{array}{c}2,64 \\
1,68 \\
6,74 \\
0,42 \\
0\end{array}$ & $\begin{array}{l}54,4 \\
21 \\
190 \\
16,3\end{array}$ & $\begin{array}{c}2,72 \\
1,76 \\
8,26 \\
0,42 \\
0\end{array}$ & $\begin{array}{c}53,4 \\
22,9 \\
145 \\
16,5\end{array}$ & $\begin{array}{c}2,67 \\
1,89 \\
6,30 \\
0,42 \\
0\end{array}$ & $\begin{array}{c}44,8 \\
25,9 \\
155 \\
16 \\
0,50\end{array}$ & $\begin{array}{l}2,24 \\
2,14 \\
6,75 \\
0,41 \\
0,03\end{array}$ \\
\hline Extrait sec & 740 & & 764 & & 736 & & 700 & \\
\hline Dureté & $\mathrm{d}^{\circ} \mathrm{Fr}$ & meq & $d \circ P_{T}$ & meq & $\mathrm{d}^{0} \mathrm{FT}$ & meq & $d^{\circ} \mathrm{Fr}$ & meq \\
\hline
\end{tabular}

taines données, applicables au Ferlo, proviennent du C.R.Z. de Dahra. Toutefois, les résultats des analyses chimiques n'apportent qu'une approximation dans la connaissance du problème de l'alimentation des herbivores. Des raisons multiples limitent leur signification (35) :

- en premier lieu, le nombre des analyses s'avère insuffisant pour donner des valeurs statistiques certaines:

- la nature et la proportion des différentes espèces végétales consommées sont imprécises ;

- Ia plante est rarement utılısée dans sa totalité, les feuilles et les parties les moins ligneuses étant les plus recherchées ;
- enfin, le rôle tenu par le «pâturage aérien » est d'appréciation difficile.

L'échantilion ne représente donc qu'imparfaitement la composition globale du pâturage et plus difficilement encore l'aliment ingéré. Sı l'on veut considérer le nutriment, l'imprécision s'aggrave encore. L'étude de la digestibilité des diverses espèces végétales est à ses débuts. Le calcul de la valeur fourragère s'effectue donc à partir de données purement théoriques.

Ces réserves étant faites, que peut-on dégager de ces analyses?

Tout d'abord, le faut dominant réside dans la brièveté du cycle végétatif. Dès les premières pluies l'herbe jaillit du sol. parvient à maturité, puis se dessèche rapidement. Au cours de la 
TABLEAU NOVII

Analyse d'eau de forage (B.R.G.î.) (suite et fin)

\begin{tabular}{|c|c|c|c|c|c|c|c|c|}
\hline $\begin{array}{l}\text { Echantillon } \\
\text { Date du prélèvement }\end{array}$ & \multicolumn{2}{|c|}{15.9 .61} & \multicolumn{2}{|c|}{$\begin{array}{l}\text { Lagbar } \\
28.11 .61\end{array}$} & \multicolumn{2}{|c|}{8.3 .62} & \multicolumn{2}{|c|}{13.1 .62} \\
\hline \multicolumn{9}{|l|}{ NO I R H } \\
\hline $\mathrm{pH}$ & \multicolumn{2}{|c|}{7,9} & \multicolumn{2}{|c|}{7,6} & \multicolumn{2}{|c|}{8,0} & \multicolumn{2}{|c|}{7,8} \\
\hline Teneur per litre & $\mathrm{mg}$ & meq & mg & meq & mg & meq & mg & meq \\
\hline $\begin{array}{c}\mathrm{Cl}_{4} \\
\mathrm{SO}_{4} \\
\mathrm{CO}_{3} \mathrm{H} \\
\mathrm{CO}_{3} \\
\mathrm{NO}_{3} \\
\mathrm{~F} \\
\mathrm{SiO}_{2} \\
\mathrm{P}_{2} \mathrm{O}_{5} \\
\text { Total anions }\end{array}$ & $\begin{array}{l}71 \\
23 \\
14\end{array}$ & $\begin{array}{c}2,00 \\
0,48 \\
3,80 \\
0 \\
0 \\
0,02 \\
6,30\end{array}$ & $\begin{array}{r}71 \\
50 \\
120\end{array}$ & $\begin{array}{c}2,00 \\
1,04 \\
4,00 \\
0 \\
0 \\
0\end{array}$ & $\begin{array}{r}77,2 \\
6,1 \\
117\end{array}$ & $\begin{array}{c}2,12 \\
0,20 \\
3,80 \\
0 \\
0 \\
0 \\
6,22\end{array}$ & $\begin{array}{c}74,5 \\
38,4 \\
117 \\
\quad T \\
0,2\end{array}$ & $\begin{array}{c}2,10 \\
0,80 \\
3,90 \\
0 \\
0 \\
0,01 \\
6,81\end{array}$ \\
\hline $\begin{array}{l}\mathrm{Ca}+ \\
\mathrm{Mg}+ \\
\mathrm{Na}+ \\
\mathrm{K}+ \\
\mathrm{NE}+4 \\
\mathrm{Fe} \\
\mathrm{Al}_{2} \mathrm{O}_{3}\end{array}$ & $\begin{array}{c}14,2 \\
5 \\
120 \\
14,2 \\
T\end{array}$ & $\begin{array}{c}0,72 \\
0,40 \\
5,22 \\
0,36 \\
0 \\
\\
6,70\end{array}$ & $\begin{array}{c}16 \\
10 \\
120 \\
14,2\end{array}$ & $\begin{array}{l}0,80 \\
0,80 \\
5,22 \\
0,39\end{array}$ & $\begin{array}{c}13,8 \\
9,9 \\
108 \\
15,4\end{array}$ & $\begin{array}{c}0,69 \\
0,82 \\
4,70 \\
0,39 \\
0\end{array}$ & $\begin{array}{c}14,4 \\
9,2 \\
125 \\
14,9 \\
0,5\end{array}$ & $\begin{array}{l}0,72 \\
0,76 \\
5,44 \\
0,38 \\
0,03\end{array}$ \\
\hline Extrait sec & 420 & & 9.412 & & 404 & & 516 & \\
\hline Dureté & $d^{\circ} \mathrm{Fr}$ & meq & $d \circ r$ & meq & $d \circ F_{r}$ & meq & $\mathrm{d}^{\circ} \mathrm{Fr}$ & meq \\
\hline
\end{tabular}

saison humide et de la saison sèche, les bovins sont soumis à une alimentation essentiellement différente. Le taux des éléments nutritifs et plus encore leur digestibilité varient énormément dans l'année.

Le tableau 8 donne des valeurs obtenues avec des prélèvements récoltés les uns en fin de cycle végétatif, les autres pendant la saison sèche.

L'examen de ces chiffres permet de noter tout d'abord une déshydratation rapide ef presque totale des fourrages. En quatre mois, I'humidité moyenne est passée de 68 p. 100 à 5 p. 100.

Le taux des matières azotées, déjà faible à la bonne saison, diminue sensiblement dans les pailles sèches.

La valeur énergétique moyenne obtenue à partir de quelques expériences de digestibilité effectuées (*) est de 0,45 U. F. par kg de matière sèche à la saison humide. Elle tombe à 0,15 ou 0,20 U. F. dès le mois de janvier.

Le résultat le plus significatif porte sur les taux de phosphore et de calcium fournis par ces analyses. On remarque, à la fois, la faiblesse de la teneur en phosphore et la valeur élevée du rapport phospho-calcique.

Des conclusions semblables ressortent des compositions chimiques des fourrages portées dans les tableaux 9 et 10 .

Les travaux de LABOUCHE et MAINGUY, confirmant ceux effectués en Afrique du Sud (48),

(*) Travail èn cours à la section de chimie nutrition du Laboratoire national de l'Elevage de Dakar (VALENZA J. ef BOUDERGUES R,). 
TABLEAU NOYIII

\begin{tabular}{|c|c|c|c|c|c|c|}
\hline & \multicolumn{3}{|c|}{$\begin{array}{l}\text { Fourrages récoltés fin } \\
\text { saigon des pluies }\end{array}$} & \multicolumn{3}{|c|}{$\begin{array}{c}\text { Fourrazes récoltés en } \\
\text { salson seche }\end{array}$} \\
\hline ' & $\begin{array}{c}\text { Dahra } \\
13.9 .63\end{array}$ & $\begin{array}{r}\text { Dahra } \\
21.9 .63\end{array}$ & $\begin{array}{l}\text { Loumbol } \\
30.9 .63\end{array}$ & $\begin{array}{l}\text { Lagbar } \\
18.12 .64\end{array}$ & $\begin{array}{c}\text { Dehra } \\
13.1 .64\end{array}$ & $\begin{array}{c}\text { Dahra } \\
18.2 .64\end{array}$ \\
\hline $\begin{array}{l}\text { Matières sèches } \\
\text { p.100 récolte }\end{array}$ & 23,43 & 28,59 & 41,11 & 93,44 & 93,88 & 95,69 \\
\hline Mat. azotéen totales & 6,68 & 5,25 & 4,08 & 2,98 & 1,97 & 2,14 \\
\hline Cellulose & 39,65 & 35.15 & 39,4 & 41,19 & 43,34 & 42,09 \\
\hline Mat. Erassea totales & 1,71 & 1,21 & 1,6 & 1,32 & 1,70 & 1,38 \\
\hline Mat. minérales totalos & 6,67 & 7,29 & 6,03 & 11,04 & 5,05 & 3,57 \\
\hline Extractif non azoté & 45,29 & 51,10 & 48,89 & 38,89 & 47,90 & 46,51 \\
\hline Calcium & 0,600 & 0,609 & 0,460 & 0,24 & 0,56 & 0,29 \\
\hline Phosphore & 0,076 & 0,052 & 0,105 & 0,025 & 0,04 & 0,019 \\
\hline $\mathrm{Ca} / \mathrm{P}$ & 8,0 & 11,71 & 4,38 & 9,60 & $14, \infty$ & 15,26 \\
\hline
\end{tabular}

Remarque : Les résultats sont exprimés en p.100 de matièrea sèches.

ont montré que la teneur des plantes en acide phosphorique croît jusqu'à la floraison. Les sels de cet acide s'accumulent alors dans les fevilles. Dès que commence la déshyơratation, l'enrichissement des parties supérieures du végétal s'arrête, puis le taux en phosphore diminue, les phosphates gagnant la racine et même retournant au sol.

LEWITE (7) a observé en outre que l'appauvrissement en phosphore, sous l'effeł de la sécheresse, s'accompagne d'une augmentation de la teneur en calcium.

Ces constatations sont valables pour la région qui nous intéresse. Pendant 7 mais de l'année, l'animal consomme un aliment ligneux et indigeste contenant peu de phosphore et beaucoup de calcium.

Or les quantités de phosphore et de calcium apportées par l'alimentation doivent répondre à deux conditions (19). La première concerne un besoin minimum exprimé en poids, la seconde implique qu'un certain rapport, variable suivant les espèces, doit exister entre ces deux éléments.

Pour THEILER (47), la quantité minimum de phosphore nécessaire journellement, exprimée en $\mathrm{P}_{2} \mathrm{O}_{5}$ est de $27 \mathrm{~g}$. Au-dessous de cette limite, l'ostéophagie s'installe $(15,17)$.

Les fourrages sont capables de satisfare ces exigences que s'ils contiennent :

- 0,45 p. 100 d'acide phosphorique (rapporté à la matière sèche), lorsqu'ils sont constitués par des herbes jeunes, avec un équivalent amidon de 60 ,

- 0.15 p. 100 d'acide phosphorique lorsqu'ils ne sont plus que des pailles, où la valeur énergétique est tombée à 20 dans la même unité.

Le besoin particulier des bovins en phosphore est un falt connu. Pour cette espèce, la valeur du rapport $\mathrm{Ca} / \mathrm{P}$ doit être comprise entre 0,75 et $1,2(19)$.

Les analyses montrent que, dans le Ferlo, les fourrages ne remplissent aucune de ces deux conditions. Pendant la longue période de saison sèche on ne retrouve pas dans la ration le minimum de phosphore indispensable ef le rapport phospho-calcique offre une valeur nettement défavorable. L'apparition du trouble nutritionnel est donc facilement explicable.

Les conclusions se retrouvent dans le tableau 11 extrait de l'étude de RAYNAL J. (35).

\section{F. - OBSERVATIONS ET RECHERCHES DE PATHOLOGIE}

L'étude du milieu naturel a permis de soulıgner l'insuffisance ef le déséquilıbre phospho-calcique des sols, des eaux et des pâturages du Ferlo. Les observations suivantes mettront en lumière le refentissement sur l'animal de ces diverses déficiences. 


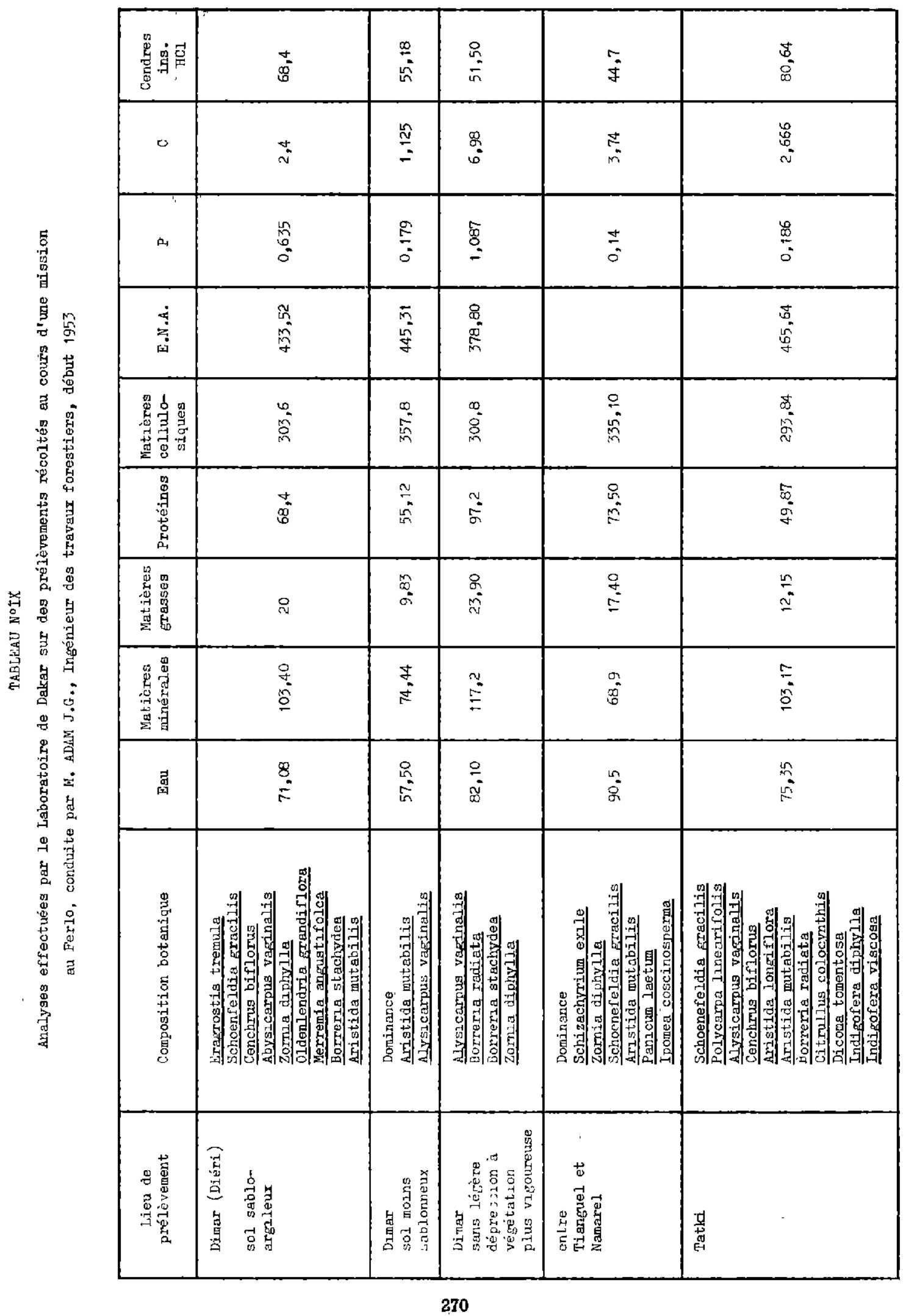


TABLEAU NOX

Analyses effectuées par le Laboratoire de Dakar sur des prélèvements récoltés au coura d'une mission au Ferlo, conduite par M. ADAM J.G., Ingénieur des travaux forestlers, début 1953 (suite)

\begin{tabular}{|c|c|c|c|c|c|c|c|c|c|c|}
\hline $\begin{array}{l}\text { Leu de } \\
\text { prélèvement }\end{array}$ & Composition botantque & Equ & $\begin{array}{l}\text { Matières } \\
\text { minérales }\end{array}$ & $\begin{array}{l}\text { Matières } \\
\text { grasses }\end{array}$ & Prutáines & $\begin{array}{l}\text { Matières } \\
\text { cellulo- } \\
\text { siques }\end{array}$ & E.N.A. & $P$ & $\mathrm{c}$ & $\begin{array}{c}\text { Cendres } \\
\text { ins. } \\
\text { HC1 }\end{array}$ \\
\hline $\begin{array}{l}\text { Me BIDI } \\
\text { foln } \\
\text { débris } \\
\end{array}$ & 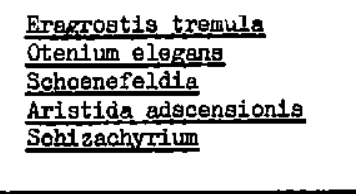 & $\begin{array}{l}55,10 \\
64,8 \\
\end{array}$ & $\begin{array}{r}62,40 \\
201,3 \\
\end{array}$ & $\begin{array}{r}6,30 \\
11,90 \\
\end{array}$ & $\begin{array}{l}21,5 \\
66,70\end{array}$ & $\begin{array}{l}356,9 \\
232,20 \\
\end{array}$ & $\begin{array}{r}497,8 \\
416,10 \\
\end{array}$ & $\begin{array}{l}1,05 \\
1,10 \\
\end{array}$ & $\begin{array}{l}1,80 \\
4,2 \\
\end{array}$ & $\begin{array}{r}47,2 \\
177,90 \\
\end{array}$ \\
\hline $\begin{array}{l}\text { Lagbar } \\
\text { sol sableux } \\
\text { argileux } \\
\text { débris }\end{array}$ & 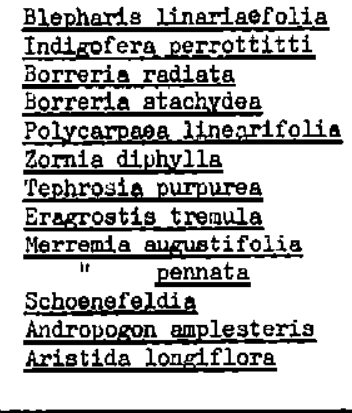 & 63,01 & 51,10 & 11,6 & 26,00 & 361,2 & 539,6 & traces & 1,80 & $\begin{array}{l}40,80 \\
41 \\
4\end{array}$ \\
\hline Sorango & 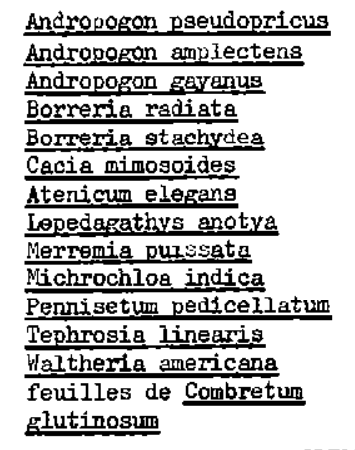 & 73,5 & 81,80 & 29,10 & 80,80 & 188,7 & 523,90 & 0,66 & 8,10 & 11,10 \\
\hline
\end{tabular}


TABLEAU NOXI

Valeur moyenne de résultats d'anglyses par groupenent végétal *

\begin{tabular}{|c|c|c|c|c|c|c|c|c|c|c|c|}
\hline groupement végétal & $\begin{array}{l}\text { matière } \\
\text { sèche }\end{array}$ & $\begin{array}{l}\text { matière } \\
\text { minérale }\end{array}$ & $\begin{array}{l}\text { matière } \\
\text { Erasse }\end{array}$ & $\begin{array}{l}\text { matière } \\
\text { protéique } \\
\text { totale } \\
\end{array}$ & cellv- & ENA & \begin{tabular}{|l|} 
matiére \\
protéique \\
digestible
\end{tabular} & $\mathrm{Cl}$ & $\mathbf{P}$ & $\mathrm{Ca} / \mathrm{P}$ & $\mathrm{UN} / \mathrm{kg}$ \\
\hline$\frac{\text { Teprrosia }}{\text { platrcarpa }}$ & 279 & 75,9 & 20,4 & 113 & 349 & 440 & 66,6 & 3,97 & 0,473 & 8,6 & 0,57 \\
\hline Monechma + Borreria & 207 & 119 & 18 & 78,2 & 357 & 423 & 39,6 & 4,58 & 0,502 & 8,9 & 0,48 \\
\hline$\frac{\text { Andropogon }}{+ \text { Monechma }}$ & 272 & 72 & 11 & 41,9 & 433 & 441 & 9,55 & 2,16 & 0,268 & 8,4 & 0,44 \\
\hline Andropogon + Zomia & 260 & 56,0 & 15 & 54,2 & 419 & 453 & 16,1 & 1,96 & 0,203 & 9,6 & 0,50 \\
\hline 2ornia & 211 & 79,1 & 15 & 108 & 364 & 433 & 63,5 & 3,98 & 0,45 & 8,8 & 0,61 \\
\hline $\begin{array}{l}\text { Dhheteroposon } \\
\text { hagerupii + Andropogon } \\
\text { psendepricus }\end{array}$ & 317 & 62,46 & 13,5 & 56,4 & 406,9 & 457 & 22,4 & 1,135 & 0,141 & 7,9 & 0,47 \\
\hline $\begin{array}{l}\text { Zornia }+ \\
\text { Schoenefeldie }\end{array}$ & 231 & 85,2 & 14,2 & 87 & 373,1 & 437 & 45,4 & 2,77 & 0,367 & 7,3 & 0.56 \\
\hline Aristide fumiculata & 800 & 70 & 11,5 & 51,2 & 493 & 458 & 20 & $0,312\}$ & 0,097 & 3,2 & 0,33 \\
\hline Bas fonds & 231 & 106 & 12,5 & 42,7 & 798 & 432 & 19,7 & 3,24 & 0.63 & 5.5 & 0.43 \\
\hline
\end{tabular}

(*) en p. 1000 dè mstière sèche

Io Le trouble nutritionnel. Hypophosphorose.

Faisant suite à des observations antérieures, une enquête systématique a été entreprise sur un certain nombre de troupeaux du Ferio.

En effet, après les premières recherches portant sur 19 prélèvements sanguins effectués dans cette région en juin/juillet 1963 et sur 4 prélèvements provenant de vaches malades originaires de Dahra et Louga transportées au laboratoire, les résultats avaient falt apparaître un taux de phosphore inorganique sanguin assez faible $(50,7 \mathrm{mg} / \mathrm{I} \pm 9,31)$ et un taux de calcium également abaissé $(83,4 \mathrm{mg} / \mathrm{l} \pm 3,60$ ). De même les analyses effectuées sur des os d'animaux morts de la maladie, présentant une teneur en lipides très basse et un rapport matière mınérale/protide inférieur à la normale, avaient permis de conclure d̀ un certain degré d'ostéomalacie.

Le troupeau de zébus du Centre de recherches zootechniques de Dahra-Djolof qui, recevant une alımentation complémentée, peut être considéré comme non carencé, a constitué le terme de comparaison.

Cette enquête a comporté deux périodes d'études: l'une au mois de décembre quand, après la fin de la saison des pluies, les pâturages sont abondants et les animaux au mieux de leur forme, l'autre au mais de juin à la fin de la saison sèche.

La première période a porté sur les troupeaux des points survants :

- Forage de Lagbar $\left(15^{\circ} 50^{\prime} \mathrm{N}-14^{\circ} 48^{\prime} \mathrm{W}\right)$, campement de Loumboul-Kélely (15048' $\mathrm{N}$ $\left.14038^{\prime} \mathrm{W}\right)$, campement de Loubel-Kalidy $\left(15^{\circ} 50^{\prime} \mathrm{N}-14^{\circ} 39^{\prime} \mathrm{W}\right)$, campement de Tilel (15048' $\left.\mathrm{N}-14052^{\prime} \mathrm{W}\right)$.

- La deuxième période a porté, autant qu'il était possible, sur les mêmes animaux. Ont été élımınés les campements de Loumboul-Kélely et L'oubel-Kalidy dont les troupeaux avaient transhumé au Oualo pendant la saison sèche et n'étaient pas encore revenus ; ont été ajoutés les troupeaux du campement de Khadar $\left(15^{\circ} 44^{\prime} \mathrm{N}-14^{\prime} 45^{\prime} \mathrm{W}\right)$ et du forage de Yaré-Lao $\left(16^{\circ} 02^{\prime} \mathrm{N}-14^{\circ} 33^{\prime} \mathrm{W}\right)$ dépendant du cercle de Podor.

Les examens faits sur le troupeau de Dahra et lors de la première partie de l'enquête ont porté sur les protéines plasmatiques totales, le phosphore inorganique plasmatique, le calcium libre plasmatique, le $\mathrm{pH}$ urinaire, 
TABLEAU NOXII

Résulltats de la première période d'enquête (intervalie de confiance de la moyenne au niveau 0,95 )

\begin{tabular}{|c|c|c|c|c|c|c|c|c|c|c|c|c|}
\hline \multirow[b]{2}{*}{ Phasphorémie en mg/l } & \multicolumn{2}{|c|}{ IAGBAR } & \multicolumn{2}{|c|}{ TILEL } & \multicolumn{2}{|c|}{ LOTREL } & \multicolumn{2}{|c|}{ LOUMBOUL } & \multicolumn{2}{|c|}{$\begin{array}{l}\text { moyense } \\
\text { générale }\end{array}$} & \multicolumn{2}{|c|}{ DAHRA } \\
\hline & 45 & $\begin{array}{l}52,8 \\
\pm 4,33\end{array}$ & 25 & $\begin{array}{l}52,7 \\
\pm 4,73\end{array}$ & 18 & $\begin{array}{l}50,3 \\
\pm 4,07\end{array}$ & 29 & $\begin{array}{l}56.7 \\
\pm 5 . \mathrm{B} 6\end{array}$ & 117 & $\begin{array}{l}53,4 \\
\pm 2,40\end{array}$ & 57 & $\begin{array}{l}60,6 \\
\pm 3,35\end{array}$ \\
\hline Calcémie en $\mathrm{mg} / \mathrm{l}$ & 41 & $\begin{array}{l}101,8 \\
\pm 2,20\end{array}$ & 25 & $\begin{array}{l}102,3 \\
\pm 2,24\end{array}$ & 18 & $\begin{array}{l}102,0 \\
\pm 3,14\end{array}$ & 30 & $\begin{array}{l}103,3 \\
\pm 3,11\end{array}$ & 114 & $\begin{array}{l}102,3 \\
\pm 1,28\end{array}$ & 57 & $\begin{array}{l}103,1 \\
\pm 0,90\end{array}$ \\
\hline Protéines totales en $\mathrm{E} / \mathrm{l}$ & 40 & $\begin{array}{l}86,3 \\
\pm 2,91\end{array}$ & 25 & $\begin{array}{l}83,9 \\
\pm 3,71\end{array}$ & 17 & $\begin{array}{l}84,3 \\
\pm 2,79\end{array}$ & 29 & $\begin{array}{l}90,5 \\
\pm 3,95\end{array}$ & 111 & $\begin{array}{l}86,6 \\
\pm 1,72\end{array}$ & 54 & $\begin{array}{l}84,5 \\
\pm 2,17\end{array}$ \\
\hline pH urinaire & 24 & $\begin{array}{l}8,16 \\
\pm 0,08\end{array}$ & 20 & $\begin{array}{l}8,24 \\
\pm 0,12\end{array}$ & 14 & $\begin{array}{l}8,27 \\
\pm 0,17\end{array}$ & 26 & $\begin{array}{l}0,22 \\
\pm 0,19\end{array}$ & 84 & $\begin{array}{l}8,21 \\
\pm 0,07\end{array}$ & 15 & $\begin{array}{l}8,24 \\
\pm 0,04\end{array}$ \\
\hline P uringire & & & & & & & & & & & & \\
\hline $\begin{array}{l}\text { créatinine urinaire } \\
\text { en } \mathrm{mg} / \mathrm{g}\end{array}$ & 29 & $\begin{array}{l}14,6 \\
\pm 3,16\end{array}$ & 16 & $\begin{array}{l}14,3 \\
\pm 4,85\end{array}$ & 14 & $\begin{array}{l}15,1 \\
\pm 3.57\end{array}$ & 22 & $\begin{array}{l}22,5 \\
\pm 6,73\end{array}$ & 81 & $\begin{array}{l}16,9 \\
\pm 2,35\end{array}$ & 37 & $\begin{array}{l}19,7 \\
\pm 2,57\end{array}$ \\
\hline
\end{tabular}

Rerasque : Le rapport Ca urinaire/eréatinine urinaire est beaucoup trop inconstant pour que le calcul d'une moyenne soit possible.

TABLEAU H० XIII

Résultats de la aeurième période d'enquete (intervalle de confiance de la moyenne au niveau 0,95 )

\begin{tabular}{|c|c|c|c|c|c|c|c|c|c|c|}
\hline \multirow[b]{2}{*}{ phosphorénite en $\mathrm{mg} / \mathrm{l}$} & \multicolumn{2}{|r|}{ LAGBAR } & \multicolumn{2}{|c|}{ TILEL } & \multicolumn{2}{|c|}{$\begin{array}{c}\text { moyenne } \\
\text { LAGBAR-TILEL }\end{array}$} & \multicolumn{2}{|c|}{ KHADAR } & \multicolumn{2}{|c|}{ YARE-LAO } \\
\hline & 37 & $\begin{array}{l}49,5 \\
\pm 3,95\end{array}$ & 15 & $\begin{array}{l}45,2 \\
\pm 8,50\end{array}$ & 52 & $\begin{array}{l}48,2 \\
\pm 1,95\end{array}$ & 41 & $\begin{array}{l}47,0 \\
\pm 3,47\end{array}$ & 54 & $\begin{array}{l}35,2 \\
\pm 4,05\end{array}$ \\
\hline calcémie en mg/l & 37 & $\begin{array}{l}101.9 \\
\pm 1.82\end{array}$ & 15 & $\begin{array}{l}100,3 \\
\pm 2,31\end{array}$ & 52 & $\begin{array}{l}101,4 \\
\pm 0,72\end{array}$ & $4 t$ & $\begin{array}{l}93,6 \\
\pm 1,95\end{array}$ & 54 & $\begin{array}{l}97,8 \\
\pm 1,39\end{array}$ \\
\hline protéines totales en $g / 1$ & 37 & $\begin{array}{l}69.5 \\
\pm 2,16\end{array}$ & 15 & $\begin{array}{l}71,1 \\
\pm 3,96\end{array}$ & 52 & $\begin{array}{l}69,9 \\
\pm 0,72\end{array}$ & 41 & $\begin{array}{l}63,4 \\
\pm 2,30\end{array}$ & 54 & $\begin{array}{l}71.1 \\
\pm 2,07\end{array}$ \\
\hline $\begin{array}{l}\text { pression osmotique du } \\
\text { plasms en milliosmoles }\end{array}$ & 37 & $\begin{array}{l}284,9 \\
\pm 4,18\end{array}$ & 15 & $\begin{array}{l}286,2 \\
\pm 6,12\end{array}$ & 52 & $\begin{array}{l}285.3 \\
\pm 0,65\end{array}$ & 41 & $\begin{array}{l}280.9 \\
\pm 3,78\end{array}$ & 54 & $\begin{array}{l}289,6 \\
\pm 2,22\end{array}$ \\
\hline
\end{tabular}


le rapport $\frac{\text { phosphore urinaire }}{\text { créatinine urinaire }}$ et le rapport calcium urinaire

créatinine urinaire

Le rapport constituant urinaire/créatinine urinaire a été introduit en supposant constante l'excrétion de créatinine pour éliminer le facteur de concentration urinaire qu'il était impossible d'évaluer. Lors de la deuxième période d'enquête, les prélèvements d'urine, assez mal supportés par les animaux et très peu appréciés des éleveurs peuls, ont été supprimés. La détermination de la pression osmotique a été ajoutée à la liste précédente.

\section{Résultats.}

Ils sont exposés dans les tableaux 12 et 13 .

\section{Hypophosphorose.}

La comparaison des moyennes obtenues à Dahra et au Ferlo au cours de la première période permet d'établir que seule la phosphorémie est significativement différente entre les deux groupes de bovins $(\dagger=7,249 P<0,02)$. Les toux de la calcémie, de la protéinémie et de la phosphaturie ne le sont pas. Il est à noter que dons le cas de la phosphaturie, le troupeau de Loumboul-Kélely apporte une perturbation, car, comparé aux autres troupeaux, il en est significativement différent $(t=2,434 \mathrm{P}<0,05)$ malgré un intervalle de confiance très étendu. Sa suppression des calculs rend l'excrétion de phosphore des autres troupeaux de la région très significativement différente de celle du troupeau de Dahra $(t=2,606 \mathrm{P}<0,01)$.

$L$ 'hypophosphorose des troupeaux de la région de Lagbar est donc confirmée, même après la saison des pluies, lorsque les pâturoges sont les plus riches. Elle se traduit par un taux de phosphore inorganique plasmatique et une excrétion de phosphates abaissée par rapport aux normes d'un troupeau non carencé.

\section{Variation saisonnière.}

Du fait qu'il n'o éfé possible de retrouver que deux des quatre troupeaux sélectionnés à la première période de l'enquête, la comparaison des deux périodes ne comprend pour le calcul de la moyenne de la seconde que les campements de Lagbar et Tilel. Ceux-ci ne sont jamais significativement différents entre eux (même pour le phosphore inorganique plasmatıque où $t=1,04$ pour $52^{\circ}$ de liberté).

Entre les deux périodes de l'enquête la seule différence significative a porté sur les protéines totales du plasma $(t=10,41 \mathrm{P}<0,01)$ ce qui est, semble-t-il assez normal, eu égard aux conditions climatiques et alimentaires rencontrées au cours de cette seconde période.

II semble donc que ie taux de phosphore inorganique plasmatique ne varie pas entre le mois de décembre ef le mois de juin. II existe donc, dans les troupeaux de cette région, une hypophosphorémie manifeste et en quelque sorte « installée ».

\section{Variation géographique.}

On remarque d'autre part des différences significatives entre les moyennes de troupeaux particuliers :

1) le troupeau de Loumboul-Kélely dont la phosphorémie et la phosphaturie sont peu différentes de celles du troupeau de Dahra :

2) le troupeau de Khadar qui montre un effondrement du taux de protéines plasmatiques ef une basse sensible du taux de calcium, cependant que le taux de phosphore inorganique reste comparable à celui de Lagbar et Tilel $(t=4,61$ pour les protéines plasmatiques, $\dagger=6,34$ pour le calcium);

3) le troupeau de Yaré-Lao comparable à celui de Lagbar au point de vue protidique présente un taux de phosphore inorganique plasmatique singulièrement abaissé $(t=4,74 \mathrm{P}$ $<0,01)$. Il en est de même pour le colcium $(t=3,54 \mathrm{P}<0,01)$. Ce troupeau a été particulièrement atteint par la maladie.

Des conditions édaphiques particulières (Loumboul-Kélely est installé au bord d'une mare), des conditions d'élevage différentes (ce même troupeau transhume au Oualo en saison sèche), des conditions écologiques variant légèrement pourraient expliquer de telles divergences entre les troupeaux géographiquement peu éloignés les uns des autres (distance Lagbar/Yaré$\mathrm{LaO}=45 \mathrm{~km}$ ).

\section{$2^{\circ}$ Etude de la toxémie. Botulisme.}

Les recherches portant sur la mise en évidence d'une toxémıe d'origine botulique sont actuelle- 
ment en cours d'exécution. Des résultats ont été obtenus, mass ils sont encore incomplets. Les isolements de la toxine et du germe anaérabie en cause, Clostridium botulinum, à portir de prétèvements provenant d'animaux à l'agonie ou de cadavres permettront seuls d'apporter une conclusion définitive*. A l'heure actuelle, les travaux ont porté sur:

a) la reproduction de la maladie naturelle chez le zébu à partir de produits ingérés récoltés sur bovins ayant succombé à la forme aiguë de la maladie des forages ;

b) l'emploi de la sérothérapie antibotulique $C$ et $D$ dans le traitement d'anımaux malades ;

c) des essais de vaccination en zone d'endémıcité à l'aide des anatoxines $C$ et $D$;

d) la reproduction da la maladie chez des souris inoculées avec un filtrat d'une culture mıxte stérile:

e) une expérience de séro-neutralısation pratiquée chez cette espèce de laboratoire. a) Reproduction de la maladie sur zébu au laboratoire.

Au cours d'une des toutes premières tournées effectuées au forage de Lagbar, des prélèvements, en vue d'une expérience préliminaire, furent pratiqués sur des carcasses de bovins morts en brousse. Ils étalent essentiellement constitués de lambeaux de muscles noirâtres, plus ou moins desséchés, adhérents aux os ou à la peau. Des morceaux de viande et d'ossements putréfiés furent également recueillis.

La presque totalité de ces produits, après broyage et mise en suspension en sérum physiologique, fut admınıstrée à la sonde œsophagienne à trois bovins.

Deux veaux moururent sans présenter de signes de botulısme. Le troisième succomba au bout de 4 jours en présentant des symptômes de paralysie des membres, de la langue, du pénis, qui rappellent le tableau clinique de la maladie des forages.

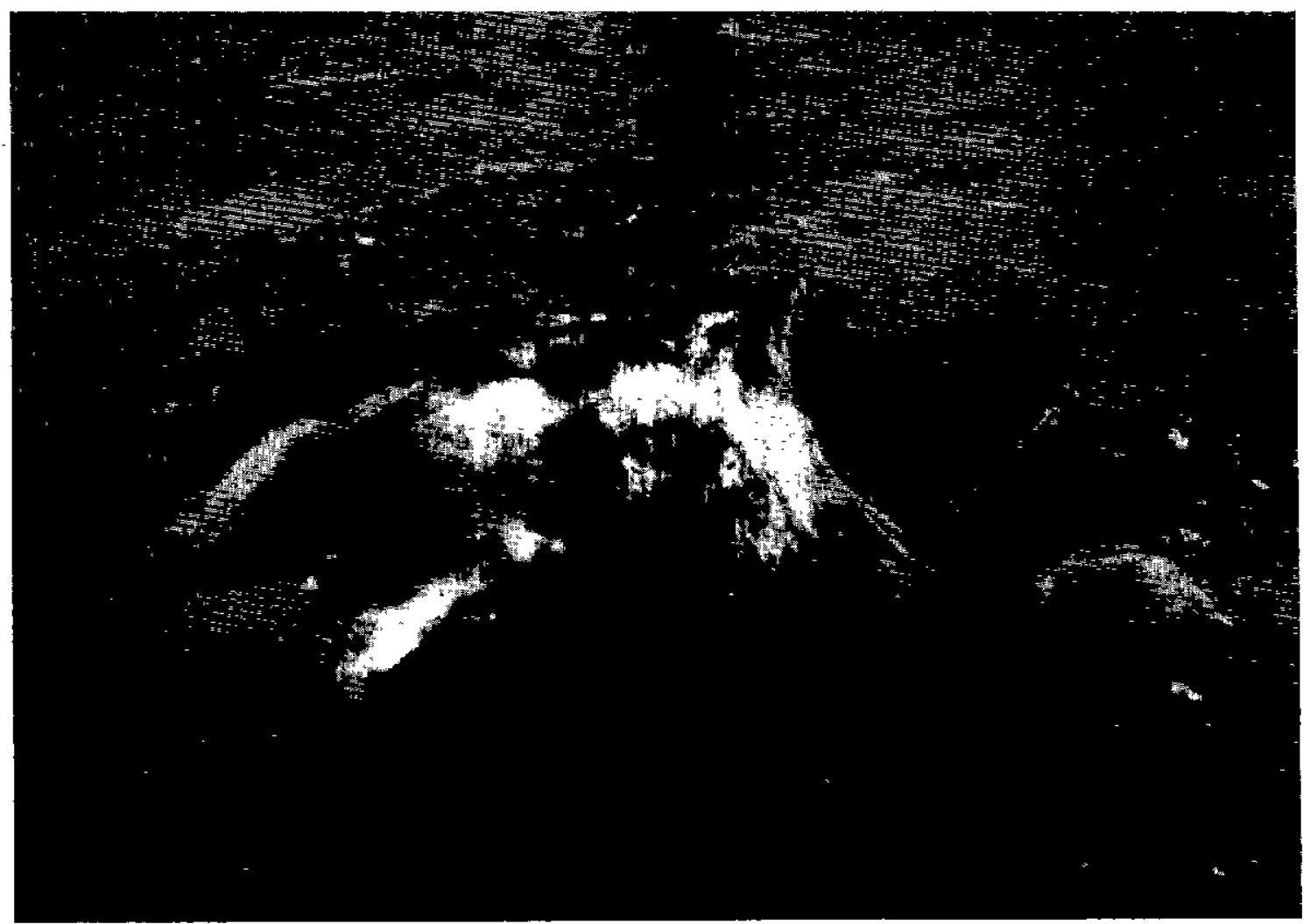

Phato $n^{\circ}$ 5. - Exemple de nécrophagie.

* N.D. L. R. - Ce diagnostıc bactériologique est maintenont effectué ; il s'agit de Clostridium botulinum type C. Une prochaine publıcation complèrera à ce sujet, ce premıer articie. 


\section{b) Sérothérapie antibotulique $C$ et $D(*)$.}

En raison du prix élevé du sérum antibotulique bivalent, l'expérımentation a porté sur une quinzaıne de cas. Bien souvent, il a été impossible de renouveler l'intervention comme Il eût été utıle de le faire. En règle générale, une seule injection de $200 \mathrm{ml}$ de sérum par voie souscutanée a été pratiquée. Nous rapportons ici quelques observations :

\section{Observation $n^{\circ} l$.}

L'animal présente des symptômes depuis 2 jours : ptyalisme, allure «piquée », titube légèrement. Dans les 8 jours qui suivent le traitement, une amélioration se dessine et l'animal très omaigri reprend sa place au sein du troupeau.

\section{Observation no 2.}

Vache ayant vélé quelques jours auparavant. Demeure couchée en brousse. Avec l'aide des éleveurs le relevé est encore possible et l'animal se déplace lentement. L'œil est enfoncé, larmoyant, le mufle sec et les naseaux souillés de jetage abondant.

Après injection du sérum antibotulique le comportement redevient normal et tous les signes pathologiques disparaissent.

\section{Observation $n^{\circ} 3$.}

Taureau de 4 ans, en décubitus depuis 3 jours. Relevé encore possible lorsque l'anımal y est poussé. La langue reste pendante après extirpation manuelle. Des croûtes épaisses recouvrent les narines.

L'injection de sérum n'ayant produit aucun effet, le taureau est abattu 3 jours après.

\section{Observation $n^{\circ} 4$.}

Vache en décubitus sterno-abdominal depuis 2 jours. Tête en position d'auto-auscultation. N'absorbe plus aucune nourriture depuis le début de la maladie. Ptyalisme abondant, naseaux souillés, paralysie de la langue.

Quatre heures après l'injection de sérum le malade s'abreuve gloutonnement, la déglutition étant à nouveau possıble. Exceptionneliement, le traitement est renouvelé le lendemaın. L'appétif et la rumination réapparaissent. II n'en va

${ }^{*}$ ) Le sérum antibotulique ainsi que les anatoxines bivalentes $C$ et $D$ proviennent de l'Institul Pasteur de Paris. pas de même de la motricité des membres et 3 mois après l'animal est toujours paralysé.

\section{Observation $n^{\circ} 5$.}

Elle porte sur 2 génisses présentant tous les symptômes d'une évolution arguë. Ces animaux ont été surpris quelques jours auparavant en train d'absorber des fragments d'os provenant d'un cadavre de bovin mort.

L'une reçoit $150 \mathrm{ml}$ de sérum, tandis que l'autre est laissée sans traitement. Au bout de 8 jours, la première a rejoint le troupeau, la seconde ne tarde pas d̀ succomber.

\section{Observation $n^{0} 6$}

Génisse en décubitus, relevé impossible, jetage, larmoiement et ptyalisme abondant.

L'injection de $150 \mathrm{ml}$ de sérum entraine la régression des symplômes au bout de 5 jours.

Les observations précédentes portent sur des cas à évolution rapide. Celles qui suivent intéressent des exemples présentant une allure chronique aboutissant à une paralysie des membres. Cet état, fréquent dans le Ferlo, sur de vieux animaux et en fin de saison sèche, peut être la conséquence tout aussi bien d'une malnutrition générale que de l'action d'une toxine.

\section{Observation $n^{\circ} 7$.}

Vache âgée, en décubitus depuis plus de 10 jours. Etat de dénutrition extrême, comportement léthargique, inappétence, inrumination, constipation.

L'injection de sérum semble sortir la malade de sa torpeur, la rumination reprend, les excréments sont de nouveau émis, l'appétit augmente.

\section{Observation $n^{0} 8$.}

L'intervention porte sur une génisse abandonnée sans soins depuis 14 jours. Aucune amélıoration n'est enregistrée et la mort survient quelques jours après.

\section{Observation no 9.}

Vache dans un, état d'extrême maigreur, mangeant et buvant peu, couchée depuis 10 jours. Une légère amélioration semble se manifester le lendemain de l'injection de sérum. Cependant, l'animal épuisé succombe quelques temps après. 
Alors que les nombreuses thérapeutiques instituées jusqu'alors, tant au laboratoire que sur le terrain, étaient toujours demeurées vaines, la sérothérapie antibotulique $C$ et $D$ a permis de noter, pour un certain nombre de formes aiguës, une régression des symptômes en particulier la paralysie du pharynx.

\section{c) Vaccination expérimentale avec les anatoxines} $C$ et $D$.

On s'est proposé par cette expérimentation de rechercher dans une éventuelle protection de troupeaux vaccinés, la preuve de l'intoxication botulique.

Au mois de juin 1964, 1.752 animaux de la région de Lagbar sont vaccinés suivant le protocole recommandé, soit 2 injections sous-cutanées de $10 \mathrm{ml}$ d'anatoxıne $C$ et $D$, pratiquées à un mois d'intervalle.

Ces animaux ont fait l'objet d'une surveillance exercée par les agents du Service de l'Elevage (*).

II est évidemment très difficile de tirer des conclusions précises d'expérimentations de ce genre, réalisées sur des troupeaux transhumants, qui se scindent et se redistribuent à longueur d'année, dans les diverses zones du Ferlo. De plus, quand les pertes sont signalées, on ne peut savoir si elles sont causées par la maladie étudiée ou par quelqu'autre facteur morbide.

Quoi qu'il en soit, les divers rapports parvenus du Ferlo et les observations des éleveurs de la région de Lagbar semblent indiquer que les animaux vaccinés sont restés indemnes alors que les pertes n'ont fait qu'augmenter dans les troupeaux voisıns non vaccinés.

Une preuve de l'efficacité de cette prophylaxie esł apportée par les fréquentes et pressantes interventions des propriétaires qui réclament avec insistance une vaccination générale de leurs troupeaux.

En 1965, 450 bovins, appartenant au lot expérimental de 1964, reçoıvent une nouvelle injection d'anatoxine botulique bivalente dans les mêmes conditions que l'année précédente.

(*) Nous remercions le Directeur du Service de l'Elevage du Sénégal ainsi que les agents du Secteur d'Elevage de Lınguère pour l'aide efficace qu'ils nous ont apportée au cours de ces recherches. d) Reproduction de la moladie chez des souris inoculées avec un filtrot d'une culfure mixfe stérile.

A l'occasion d'un nouveau déplacement accompli à Lagbar en mars 1965, des ensemencements sont effectués sur place à partir de prélèvements divers (foie, contenu d'anses intestinales) obtenus sur 4 bovins différents (43):

-2 cadavres, vieux de 48 heures, provenant d'anımaux dont l'un (C) aurait présenté un ptyalisme abondant ef une paralysie totale de la langue,

- 2 bovins en décubitus depuis 10 jours, sacrifiés par des éleveurs disposés à faciliter notre action.

Les cultures mixtes obtenues sur bouillon VF glucosé, sont incubées à l'étuve à $37^{\circ} \mathrm{C}$ pendant une semaine, puis filtrées sur bougie Chamberland $L_{\mathbf{3}}$.

La stérilité des filtrats recueillis est vérifiée par ensemencement d'un bouillon VF glucosé ef mis à l'étuve pendant 48 heures à $370^{\circ} \mathrm{C}$.

Avec chaque filtrat, les trois lots de souris sont inoculés par voie intrapérıtonéale $(0,15 \mathrm{ml})$.

\section{Résultats.}

24 heures après l'inoculation, les souris ayant reçu le filtrat de culture mixte de l'anse intestinale du bovin (C) présentent des symptômes typiques de paralysie flasque (photo no 6 ) et meurent dans les heures qui suivent.

Par la suite, des filtrats de subcultures obtenues à partir des germes retenus lors de notre première filtration se révèlent atoxiques. De même, à partır de ces subcultures, des inoculums sont préparés par chauffage de 30 minutes à $80^{\circ} \mathrm{C}$ et ensemencés en bouillon VF glucosé. Les filtrats de ces dernières cultures, inoculés à de nouveaux lots de sourıs n'entraînent l'apparition d'aucun symptôme paralytique chez ces animaux.

En présence de ces résultats, on est amené à formuler les hypothèses suivantes :

- Clostridium botulinum est présent dans la première culture et, par la suite, devenu atoxigène dans les différentes subcultures. Ce qui paraît peu probable.

- Le contenu de l'anse intestinale renferme non pas le germe, mais la toxine qui s'est diluée dans le boullon VF glucosé initial et qui a été inoculée après filtration sur bougie Chamberland $L_{3}$. 


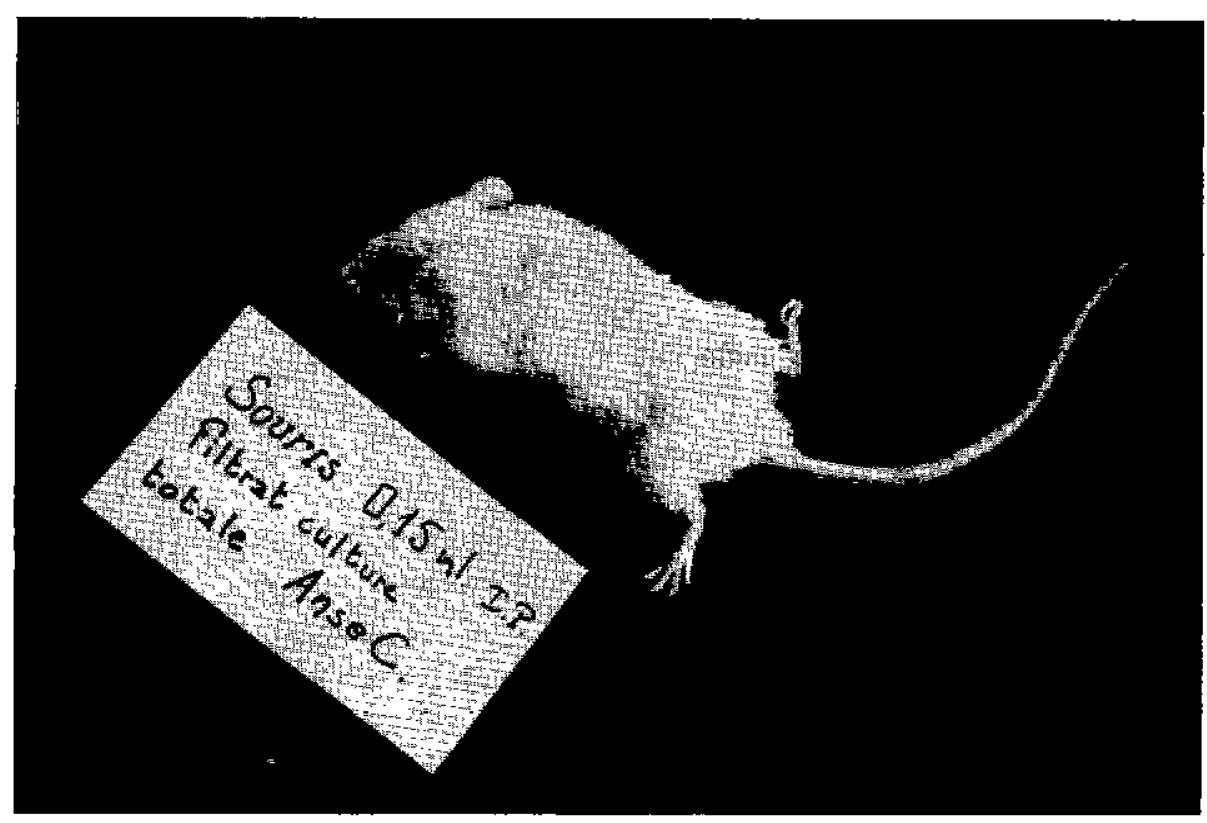

Photo $n^{\circ}$ 6. - Paralysie des membres poslérieurs d'une sourts ayani reçu le filtrat de culture mixte $C$.

\section{e) Expérience de séro-neutrolisation chez la souris.}

$1 \mathrm{ml}$ de filtrat de culture mixte de l'anse intestinale du bovin est mélangé à $1 \mathrm{ml}$ de sérum antıbotulique $C$ et à $1 \mathrm{~m} l$ de sérum antibotulique D. L'ensemble est maintenu à 30 minutes à l'étuve à $37 \circ \mathrm{C}$. Deux lots de sourıs sont ensuite immédıatement inoculées par voie intrapéritonéale, trols avec $0,30 \mathrm{ml}$ de mélange et les trois autres avec $0,10 \mathrm{ml} \mathrm{du}$ filtrat pur.

Ces trois dernières meurent dans les 48 heures en présentant une paralysie flasque débutant par les membres postérieurs. Les trois souris inoculées avec le mélange filtrat + sérum antibotulique $C$ et $D$ ne manifestent aucun symptôme.

Cette simple expérience de séro-neutralisation semble mettre en évidence la toxine botulique de façon indiscutable.

\section{DISCUSSION}

L'affection observée au Ferlo, associant dans son mécanisme pathogénique l'aphosphorose et le botulisme, ne semble pas constituer un phénomène pathologique nouveau, localısé au
Sénégal. Des observations analogues ont été effectuées dans de nombreux pays où existent les mêmes déficiences du sol.

Pour s'en convaincre, il suffit de rappeler les travaux de THEILER et de ses collaborateurs $(23,42,47)$ qui, dès 1920 , étudient le Lamsiekłe. En Australie, et touł particulièrement au Queensland, une affection analogue causée par Clostridium botulinum a été signalée $(20,49)$ de même qu'en Nouvelle-Zélonde et en Lovisiane.

Au Sénégal, il semble que l'apparition de l'aphosphorose ef du botulisme soif liée à l'évoIution relativement récente des techniques d'élevage.

Du fait de l'implantation des forages profonds qui améliorent très sensiblement les conditions d'abreuvement, les éleveurs du Ferlo réduisent l'amplitude de leurs transhumances et tendent à se fixer dans le périmètre d'influence des différentes unités hydrauliques. Les animaux consomment un fourrage insuffisant, sec et ligneux, pendant toute la durée de la saison sèche.

Dans le passé, en saison sèche, dès la disparıtion des mares, les troupeaux quittaient le Ferlo devenu inhospitalier pour gagner les rives humides du Fleuve Sénégal ou celles du Lac de 
Guiers. Certains rejoignaient même la petite côte (Mbour, Joal) ou tout au moins les zones moins arides du Ferlo Sud.

La déficience en phosphore et l'affection qu'elle entraîne apparaissent comme un cas particulier d'un problème plus général, celui des polycarences dans les zones pastorales sahélıennes où une tentative de sédentarisation humaine ef animale se dessine. Bien que les transhumances deviennent un anachronisme politique et social, elles permettaient aux herbivores de recevoir. au cours des déplacements dans des milieux différents, les éléments nutritifs variés indispensables.

La notion de supplémentation semble donc constituer la rançon de la sédentarisation.

L'inquiétude grandissante des éleveurs du Ferlo témoigne de la gravité de l'affection. Des mesures doivent être prises pour juguler les effets d'une maladie qui a déjà froppé une fraction importante du cheptel sénégalais. La vaccination par les anatoxines botuliques $C$ et $D$ dont l'efficacité a été prouvée expérimentalement. constitue un moyen de lutte immédiat. il supprime les pertes mais demeure sans effet sur le trouble nutritionnel.

A la suite des travaux préliminaires on peut admettre qu'une solution efficace réside dans la supplémentation en phosphore des animaux. L'apport de cet élément en quantité suffisante devrait permettre la disparition du pica ef tout danger de contamination pour les bovins (15. $16,17)$.

La supplémentation agıra, en outre, sur toutes les autres conséquences de la carence phosphorée, partículièrement néfastes à la production des troupeaux $(7,19)$.

Cette mesure ne devralt pas présenter au Sénégal, gros producteur de phosphate, des difficultés insurmontables. De nouvelles unités de traitement sont en voie de création, qui mettraient à la disposition de l'agriculture des engrais phosphatés. L'élevage, dont les besoins en phosphate purifié, assimilable, sont importants, devrait pouvoir profiter de cette évolution des industries chimiques.

Une telle action constituera un nouvel effort dans l'amélioration de l'élevage sahélien. Les importants investissements réclısés pour l'équipement hydraulique des zones de pâturages et ceux engagés depuis ces décades dans la lutte contre les maladies infectieuses, justifient la recherche ef l'application sur le terrain de méthodes capables de soustraire les troupeaux aux effets des carences sutritionnelles.

\section{Institut d'Elevage et de Médecine vétérnare des Poys Tropicoux. \\ Laboratorre national de l'Elevage \\ et de Recherches vétérınaires. Dakar-Hann.}

\title{
SUMMARY
}

\section{Aphosphorosis and bolulism in Senegal}

\begin{abstract}
A new animal disease has been observed in Senegal, in a northern part of the country called Ferlo. Known as «Gniedio» by the caitle owners and «maladie des forages » (deep-wells disease) by the veterinary staff, this affection recalls by its epizootiology, symptomatology and pathogeny «Lamsiekte » studied by THEILER, $H$, in South Africa.

It results of the association of a nutritional deficiency, essentially a lack of phosphorus in food, and of the action of botulism toxin.

Biochemical analysıs made in the Laboratory of Dakar have shown the state of aphosphororis presented by cattle. Chemical analysis of soils, waters and forages have revealed the same deficiency in this element.

The hypothesis of botulism has been canfirmed by the successful results obtained with the use of specific serotherapy and vaccinotion with toxoids $C$ and $D$.

Botulism toxin has been demonstrated by a sero-neutral isation test carried out in mice, but till now the isolaticn of Clostridium bofulinum has not been achieved.
\end{abstract}




\section{RESUMEN}

Afosforosis y Botulismo en el Senegal

La afección animal encontrada en el Senegal, en la región del Ferio, y llamada localmente «Gniedo » o « maladie des forages » (Enfermedad de los horadamientos) hace pensar, por su etiologia, su sintomatologia y su patogenia, al Lamsietke descrito por THEILER en Africa del Sur.

Resulta de la asociación de un desórden de la nutrición, esencjalmente una carencia en fosforo, y de una toxemia botulica.

Las análisis bioquimicas, en el Laboratorio de Dakar, mostraron el estado de afosforosis en los animales. Este elemento es tambien insuficiente en los suelos, las aguas y los forrages analizados quimıcamente.

Se confirma la hipótesis de botulismo por el exito de la seroterapia especifica $y$ de la profilaxia mediante anatoxinas botulicas $C$ y $D$.

La sero-neutralizacóin mostró la toxina botulica en el ratón, pero hasta ahora no se ha padido obtener el aislamiento de Clastridium botulinum.

\section{BIBLIOGRAPHIE}

(1) ARCHAMBAUD (J.). - Les equx souterraines de l'Afrique occidentale. Bureau Recherche Géologie et des Mines, Dakar. 1960.

(2) BARNES (J, E.) ef JEPHCOTT (B. R.). Carence en phosphore des bovins d'Australie du Nord (Phosphorus deficiency in cattle in the Northern Australia). Aust. vet. J., 1955, 31 : 302-312.

(3) BEKKER (J. G.). - Adjonction de phosphore dans l'eau d'abreuvement (Ad. ministration of phosphorus through water supply). 18th Report Dir. Vet. Services Anim. Ind. Onderstepoort, 1932, 751-790.

(4) BRASSEUR (G.). - Problèmes de l'eau au Sénégal. I. F. A. N., Ełudes sénég., 1952, 4.

(5) BREDON (R. M.). - Besoins minéraux des bovins de l'Est Africain (Mineral requirements of cattle in East Africa). Ist. Afr. Reg. Meeting on Anim. Prod. \& Health, Addis-Abeba, 1964, Work paper 38.

(6) BREMOND (R.). - Etudes des analyses d'eau des forages du Sénégal et essal d'interprétation géologique. Services des Mines du Sénégal, 1952.

(7) BRINON (A.) et PAGOT (J.). - Les carences alimentaires du bétail dans leurs rap- ports avec la pathologie animale. Rev. Elev. Méd. vét. pays trop., 1955, 2 : $223-76$

(8) CALVET (H.) et PICART (P.). - Aphosphorose ef botulisme au Sénégal. 4e Journées Médicales Dakar, 1965, à paraître.

(9) CALVET (H.) et PICART (P.). - Etude sur la maladie des forages. Lab. nat. Rech. vét., Dakar, Rap. fonction, 1964.

(10) CHEVAILER (A.). - Etudes sur les prairies de l'Ouest Africain. Rev. Bot. appl. Ajr. trop., 1933, $148: 845-92$.

(11) ANONYME. - Compte rendus de la Conférence sur les sols en régions tropicale et subtropicale (Proceeding of the first Commonwealth Conference on tropical and sub-tropical solls). Publ. Commonwealth Bur. of soils $\mathrm{scl}$. Harpenden, Engl., 1949.

(12) CRAVEN (C. P.). - Prophylaxie d'une maladie de type botulique dans le Queensland septentrional (Control of a botulism-like disease in North-Queensland). Austral vet. J., 1964, $40: 127-30$.

(13) CROQUET (J.). - Communications verbales, 1965.

(14) DEGALLIER. - Hydrologie du Ferlo occidental. Direction des Mines et de la Géologie, Dakar, 1954. 
(15) DROULISCOS (N. J.). - Besoins minéraux des bovins (Mineral requirements of cattle). Ist. Afr. Reg. Meeting on Anim. prod. \& Health, Addis-Abéba, 1964, Work paper 35.

(16) DU TOIT (P. J.) et GREEN (H. H.). Emploi du phosphate bicalcique comme source de phosphore dans l'alimentation des bovins (Dicalcium phosphate as a source of phosphorus in nutrition). Service Report South Africa, 1930.

(17) DU TOIT (P. J.), HALCEN (A. I.) et GROENWALD (J.W.). - Etudes du métabolisme minéral. $X X X \mid$. Besoins minérauX minimum des bovins (Studies on mineral metabolism. XXXI. Minimum mineral requirements of cattle). Onderstepoort J., 2 : 565-606.

(18) FAURE (J.). - Etude de quelques sols hydromorphes d̀ engorgements temporaires de la région de Bargny (Sénégal). $2^{2}$ Conf. interafr. des sols Léopoldville, 1954.

(19) FERRANDO (R.). - Les boses de l'alimentation. Vigot, 1959.

(20) FILMER (J. F.) et KULL (K. E.). - Le botulisme chez les animaux domestiques de l'Australie occidentale (Botulism in domestic animals in Western Australia). Austral. vet. J., 1937, $13: 170-72$.

(21) GRAHAM (R.) et SCHWARZE (H.). Le botulisme des bovins (Botulism in cattle). J. Bocteriol., 1921, 4 : 1-21.

(22) GROSMAIRE (J.). - Eléments de politique sylvo-pastorale au Sahel sénégalais. Service des Eaux et Forêts, Inspect. forest. du fleuve, 1957, 18 fascicules.

(23) HENNING (M. W.). - Les maladies animales en Afrique du Sud (Animal diseases in South Africa). 2nd édit., Central news agency South Africa, 1949.

(24) LABOUCHE (Cl.) et AMALOU (P.). Etude sur la maladie des forages. Lab. nat. Rech. vét., Dakar, Rap. fonction., 1962, 211-15.

(25) LABOUCHE (Cl.), CALVET (H.) et AMALOU (P.). - Etudes sur la maladie des forages. Lab. nat. Rech, vét., Dakar, Rap. fonction., 1963, 192-202.
(26) LARRAT (R.). - Hydraulique pastorale. Rap, sur le fonction. du Serv. Elev. Sénégal, 1941, 1942, 1943, 1944, 1945.

(27) LEITCH (I.) et THOMSON (J. S.). - Le métabolisme de l'eau des animaux de ferme (The water economy of farm animals). Nutr. Abstr. Rev., 1944-1945, 14: 197-223.

(28) MacFARLANE (W. V.) et MORRIS (R. J. H.). - Cycle et distribution de l'eau chez le chameau, le mouton et le kangourou en région désertique (Turn over and distribution of water in desert camels, sheeps, cattle and kangaraos). Nature (Lond.), 1963, $19: 270-71$.

(29) MALAN (A. I.) et DU TOIT (P. J.). - Comparaison des suppléments en phosphore pour la prévention de l'aphosphorose. 18 th Report Dir. vet. Services \& Anim. Ind. Onderstepoort, 1932, 677-702.

(30) MULLER (J.), - Botulisme du type C chez l'homme et les animaux. Incidence chez les bovins et les équidés (Type $C$ botulism in man and animals. Incidence in cattle and horses). Mediemsbl. danske Drylaegeforen, 1961, $44: 547-57$.

(31) MULLER (J.). - Botulisme équin ef bovin au Danemark (Equine and bovine botum lism in Denmark). Bull. off. int. Epizoot., 1963, $59: 1379-90$.

(32) PAWSON (E.). - Expériences sur la fertilité des sols en Rhodésie du Nord (Soll fertility experiments Northern Rhodesia 1950-1953). 2e Conf. int. des sols, Léopoldville, 1954, 27.

(33) PEREIRA-BARRETO (S.). - Reconnaissance pédologique du Ferlo Sud. O.R.S.T. O. M. Centre Pédol. Dakar-Hann, Rap. mission, 1964.

(34) PREVOT (A. R.), SILLIOC (R.) ef PROUTE (J.). - Etude d'un foyer de botulisme bovin dû à Clostridium botulinum. Ann. Inst. Pasteur, 1955, 88 : 513-15.

(35) RAYNAL (J.). - Etude botanique des pâturages du Centre de Recherches zootechniques de Dahra-Djolof. O.R.S.T. O. M., Paris, Sec. botan., Rap. mission, 1964. 
(36) ROBERTY (G.). — La végétation du Ferlo. Bull. I. F. A. N., 1952, $14: 777-98$.

(37) ROGERSON (A.). - Pouvoir énergétique d'aliments grossiers sur des bouvilions rationnés en eau (Energy of utilisation of poor quality roughages by waterdeprived steers). Nature (Lond.), 1963, $19: 1222$.

(38) SAGOT (R.). - Etude sur la régénération des sols et sur l'influence des engrais ef des amendements calcaires sur le mil et l'arachide. Bull. com. Etud. hist. Sci. Afr. occid., 1935, $18: 63-78$.

(39) SCHMIDT-NIELSEN (B.). - Méfabolisme de l'eau chez les mammıfères du désert (Water metabolism of desert mammals). Physiol. Rev., 1952, 32 : 135-66.

(40) SHOOP (G.). - Mise en évidence de Clostridium bolulinum type $C$ chez les bovins (Demonstration of Clostridium botulinum type $C$ in caftle). Disch. Tierärztl. Wschr, 1961, 68, : 71-72.

(41) SCOT MILLAR (J. W.). - Le botulisme en Afrique du Sud (Botulism in South Africa). South. Afr. med. J.1964, 38 : 310-15.

(42) SEDDON (H. R.). - Les maladies des animaux domestiques en Australie. (Diseases of domestic anımals in Australia). Commonwealth of Australia Depart. of Health, 1953.

(43) SERESA. - Rapport mission novembre 1959. Commercialisatıon du cheptel bovin sérégalais.

(44) SIMMONS (G. C.) et TAMMEMAGI (L.). Closiridium botulinum type $D$, agent res- ponsable du botulisme (Clostridium botulinum type $D$ as a cause of bovine botulism in Queensland). Austral. vet. J., 1964, $40: 123-127$.

(45) STEYN (D. G.). - Le traitement du botulisme (Lamsiekte) (The treatment of botulism (Lamsiekte)). J. South Afr. vet. med. Assoc., 1950, 21, 81.

(46) TAMARIN (R.) et NEEMAN (L.). - Identification de la toxine de Clostridium botulinum type $D$ dans un foyer de bofulisme chez les équins (The identification of Clostridium botulinum type $D$ toxin as the cause of an outbreak of botulism in equines). Refuoh. vet., 1962, 19, 49.

(47) TROCHAIN (J.). - Contribution à l'étude de la végétation du Sénégal. Larose, 1940.

(48) THEILER (H.), VILJOEN (P. R.), GREEN $(H . H$.$) , DU TOIT (P. J.), MEIER (H.)$ et ROBINSON (E. M.). - Le Lamsiekte (parabotulisme) des bovins en Afrique du Sud (Lamsiekte (parabotulism) in cattle in South Africa). 12th Ann. Rep. Director vet. Res. South A.fr., 1927, I2:821-1361.

(49) VINE $\left(H_{1}\right)$. - Le manque de fertilité des sols africains tropicaux est-il exagéré ? (Is the lack of fertility of tropical african soils exagerated?) 2nd Conf. interafr. des sols, Léopoldville, 1954.

(50) WEBB (R. A.). - Déficiences en éléments minéraux de quelques sols en Gambie (The mineral deficiencies of some Gambian soils). 2nd Conf. interafr. des sols, Léopoldville, 1954. 